\title{
LA FÁBULA MITOLÓGICA EN LA PLURITEMÁTICA MANIERISTA. A PROPÓSITO DE LA “SILVA AL ELEMENTO DEL AIRE” DE AGUSTÍN DE TEJADA PÁEZ ${ }^{1}$
}

\author{
María D. Martos PÉRez \\ Universidad de Málaga
}

\section{InTRODUCCIÓN}

El estudio de un género como el de la fábula mitológica en la poesía áurea española puede abordarse desde textos limítrofes a la caracterización esencialmente definidora del tal género:

El valor contrastivo y de individualidad del autor «menor» en un determinado género puede concluir en la creación de alternativas históricamente marginales, a cuyo trasluz también comprendemos mejor el género del que en su específica poética se aparta².

1 Recibido: 30-XI-2009 Aceptado: 17-II-2010

2 J. Lara Garrido, Del Siglo de Oro (métodos y relecciones), Madrid, Universidad Europea-CEES Ediciones, 1997, pág. 86. 
Desde esta atalaya crítica, a propósito de la «Silva al elemento del aire» del poeta antequerano Agustín de Tejada Páez (1567-1635), trataremos de iluminar uno de los ángulos de desarrollo de la fábula mitológica en los años iniciales del siglo XVII. Empezaremos por incardinar la propuesta poética del autor de los Discursos históricos de Antequera en ese período de transición entre la lírica renacentista y barroca que ha sido nominado como Manierismo ${ }^{3}$. El Manierismo, como estilo singular y efectivo cambio estético de lo renacentista a lo barroco se ha definido, particularmente, en el terreno de la compositio y elocutio. La defensa de actuación de mecanismos formales como fin sustantivo del arte - con la consiguiente primacía del deleite lector y el valor del ingenio del poeta como «hacedor» de ese artificio constructivo - va a impulsar una serie de cambios que cifran el Manierismo como un estilo de fluctuación y de progresividad estética de lo renacentista hacia lo barroco. Una serie de autores enmarcados entre finales del siglo XVI y principios del XVII testimonian en su práctica literaria este estilo fluctuante entre la clasicidad renacentista y la novedad barroca ${ }^{4}$.

Uno de los mecanismos formales que gozan de gran cultivo en la estética manierista es el del pluritematismo, que Emilio Orozco ha estudiado en el caso de la poesía (sonetos pluritemáticos de base, principalmente, amorosa en la obra de Góngora) y de la novela (inserción de relatos o textos poéticos en el Quijote). En estas organizaciones pluritemáticas manieristas la fábula mitológica se erige en un elemento argumental privilegiado que se debate entre la sujeción a la doctrina de la imitatio y la originalidad inventiva del autor. Junto a la fábula mitológica, la descripción de la naturaleza va cobrando una relevancia que el período barroco elevará a supremacía, y ambos argumentos sirven de contrapunto a la temática amorosa de signo petrarquista. Estos tres núcleos temáticos - lo mitológico, la descripción de la naturaleza y el marco amoroso - se integran en una construcción lógico-discursiva en la que el tema principal ofrece un mínimo desarrollo relegado a los versos finales, propiciando, así, diversos juegos intelectuales muy del gusto manierista.

Ilustraremos con una serie de textos emplazados en las dos décadas finales del XVI y los primeros años del XVII esta práctica poética de la pluritemática manierista y la funcionalidad de la fábula mitológica en su red temática, cuyos paralelos y elementos diferenciadores respecto a la composición del antequerano aspiran a iluminar, en lo posible, la efervescencia estética de inicios del XVII, que, en ocasiones, avanza

3 Entiéndase en el término en el sentido y caracterización propuesta por E. Orozco, Manierismo y Barroco, Madrid, Cátedra, 1981.

4 Paralelamente a la praxis poética, estos principios básicos se iban codificando en las retóricas y poéticas, primero italianas y después españolas. Véase A. García Berrio, «Fundamentos retóricos-poéticos en la estética del Manierismo», en A. Sotelo Vázquez (coord.) y M. C. Carbonell (ed.), Homenaje al Profesor Antonio Vilanova, Universidad de Barcelona, 1989, vol. I, págs. 279-295. 
formulaciones plenamente barrocas y en otras se retrotrae a un clasicismo de signo manierista.

\section{ENCUADRE CRÍtICO: ENTRE EL POEMA DESCRIPTIVO BARROCO, LA CONFORMACIÓN DE LA}

\section{SILVA MÉTRICA Y LOS POEMAS DE LA CREACIÓN DEL MUNDO}

La «Silva al elemento del aire» de A. de Tejada Páez se halla en el manuscrito titulado Poética silva $a^{5}$ una de las compilaciones fundamentales que jalonan la transición de la poesía del XVI al XVII y una de las colectáneas fundamentales para el conocimiento de la poesía antequerano-granadina ${ }^{6}$. La «Silva al elemento del aire» forma parte de un ciclo dedicado a los elementos, que se completa con la «Silva al elemento del fuego» de Gutierre Lobo, la «Silva al elemento del agua» de Andrés del Pozo y la «Silva al elemento de la tierra» de Pedro Rodríguez de Ardila7.

La ideación cíclica del conjunto de composiciones en que se integra, el marbete de silvas con el que éstas aparecen rotuladas $\mathrm{y}$, fundamentalmente, la cabida que tiene en ellas el procedimiento descriptivo ha llevado a la crítica a señalar estas silvas como antecedentes del poema descriptivo barroco, del que las Soledades gongorinas constituyen el paradigma más sobresaliente. A partir de aquí se ha analizado su papel en la conformación de la silva métrica, a la vez que la «Silva al elemento del aire» ha sido encuadrada entre de los poemas barrocos de la creación del mundo por su temática cosmogónica.

Así pues, recapitulando el abanico de perspectivas adoptadas por la crítica, la «Silva al elemento del aire» ha sido atendida desde cuatro vertientes: a) como antecedente del poema descriptivo barroco; b) a partir de su papel en la conformación de la silva métrica; c) como poema barroco de creación del mundo; d) como antecedente de las Soledades ${ }^{8}$, particularmente, en lo que respecta al ámbito siciliano y determinadas escenas de cetrería.

En cuanto a la consideración de estas silvas como precursoras de los poemas descriptivos barrocos fue Emilio Orozco el primero en señalar los poemas cíclicos de la

5 Ha sido editada recientemente de forma impecable por I. Osuna, Poética silva. Un manuscrito granadino del Siglo de Oro, ed. de I. Osuna, Universidad de Córdoba y Universidad de Sevilla, 2002, 2 vols.

6 J. Lara Garrido, «Los poetas de la Academia granadina (El grupo de la Poética silva)», Del Siglo de Oro (métodos y relecciones), págs. 231-249.

7 I. Osuna, op. cit., vol. I, págs. 62-108.

8 Estos puntos de conexión entre la «Silva al elemento del aire» y las Soledades gongorinas han sido señaladas por A. Egido («La silva en la poesía andaluza del Barroco» en Silva de Andalucía (Estudios sobre poesía barroca), Málaga, Diputación Provincial, 1990, pág. 53) y J. Roses («La sustancia poética del mundo: de los cuatro elementos a las Soledades», Hommage à Robert Jammes, Anejos de Criticón, 1, Toulouse, PUM, 1994, págs. 1033-1036). 
Poética silva dedicados a los elementos y a las estaciones como antecedentes dela ideación de las Soledades gongorinas como una tetralogía. Al subrayar los antecedentes literarios de las Soledades como el gran poema descriptivo barroco, el eminente gongorista pone de relieve el papel de los poetas granadinos en la conformación del género y de la particular visión de la Naturaleza que cristalizará en el Barroco, señalando que muchos de los poemas recogidos en la Poética silva «representan el verdadero arranque del poema descriptivo en lo español», aunque «en otra escala - en ese tono menor típico de lo granadino - sin la gran ambición y riqueza temática que se propone Góngora», así como constituyen los «jalones que preparan el gran conjunto del poema cíclico que realizan las Soledades» ${ }^{9}$. Asimismo, Aurora Egido, partiendo de la tesis de que la gestación de la silva métrica se fragua en los círculos poéticos andaluces, subraya la relevancia de las composiciones recogidas en la Poética silva bajo el marbete de silvas en el camino hacia la constitución del poema barroco de descripción de la naturaleza: «Su importancia, ya la hemos apuntado, es evidente, pues representan el surgir del poema descriptivo de la Naturaleza con todas sus características fundamentales» ${ }^{10}$.

Ya no desde el ámbito del poema descriptivo barroco, sino desde la conformación de la silva como forma métrica en la poesía barroca otros críticos han subrayado el interés de estas composiciones cíclicas a los elementos. J. Lara Garrido trazó los límites certeros de la delimitación del género indicando que «la presencia del término silva rotulando el cancionero y como denominación genérica de ocho composiciones plantea un problema terminológico de interés» ${ }^{11}$. Propone, pues, atender a la doble acepción del término silva en el Siglo de Oro: primero, como miscelánea, en el sentido de variedad temática, estilística o retórica («ordenación selvática») y, en segundo lugar, incardinando una de sus vías de desarrollo en la tradición estaciana: «Estas silvas métricas, con su variabilidad formal remiten, en primer término a un poeta tan conocido del grupo como Estacio, cuyas Silvae propiciaban esa experimentación al hallarse "en parte escritas en hexámetros, parte en endecasílabos falaicos, parte en estrofas arcaicas, parte en sáficas" $\gg^{12}$. Desde esta perspectiva crítica han abordado el tema estudiosos tan autorizados como Eugenio Asensio o Aurora Egido así como se han dedicado volúmenes monográficos como el coordinado por Begoña López Bueno ${ }^{13}$. Inciden

9 E. Orozco, El poema «Granada» de Collado del Hierro, Diputación Provincial de Granada, 1964, págs. 196-197. Sobre esta misma idea ya había incidido en un estudio anterior sobre la poesía del también granadino Soto de Rojas (E. Orozco, Introducción a un poema barroco granadino. De las «Soledades» gongorinas al «Paraíso de Soto de Rojas, Universidad de Granada, 1955, págs. 42-43).

10 A. Egido, «La silva en la poesía andaluza del Barroco», pág. 26.

11 J. Lara Garrido, «Los poetas de la Academia granadina (El grupo de la Poética silva)», pág. 235.

12 J. Lara Garrido, loc. cit., pág. 236.

13 E. Asensio, «Un Quevedo incógnito. Las "silvas"», Edad de Oro, II, 1983, págs. 13-48; A. Egido, «La silva en la poesía andaluza del Barroco»; y B. López Bueno (ed.) La silva. I Encuentro Internacional sobre poesía del Siglo de Oro, Universidad de Sevilla y Universidad de Córdoba, 1991. 
estos estudios en la indefinición que acompaña al término silva hasta que el modelo gongorino fija las características del género, sirviendo hasta ese momento para nominar poemas de distinta factura, bien marcados por el lirismo, el contenido descriptivo o la impronta didáctica, haciendo difícil la posibilidad de abstraer una caracterización que defina globalmente los poemas que aparecen rotulados bajo tal término. No obstante, puntualiza E. Asensio que «hay un rasgo que las mejores de ellas comparte, el gusto por la descripción, por la ékfrasis o pintura concreta y vívida de objetos naturales y artísticos, de lugares geográfica o históricamente ambientados, con valor propio, no subordinados a la dinámica narrativa aunque sí a los sentimientos y reflexiones» ${ }^{14}$. También Emilio Orozco, refiriéndose a las composiciones así rotuladas en la Poética silva, señaló que es en el contenido descriptivo de la naturaleza donde el término silva encuentra su dimensión significativa como «selva o bosque, esto es, naturaleza en libre desorden y variedad ${ }^{15}$. Igualmente Aurora Egido subrayó el camino que estas silvas abrieron hacia el barroco en lo que a la temática se refiere - pues formalmente optan por metros tradicionales: la octava y le terceto - al cultivar esa tendencia descriptiva que marcará el desarrollo de la silva métrica en general y de las Soledades gongorinas en particular ${ }^{16}$. Otros críticos vuelven a incidir en los aspectos ya señalados. J. Montero Delgado y P. Ruiz Pérez proponen la categorización de estas silvas en una modalidad que denominan silva/selva, esto es, "poemas de cierta extensión compuestos en octavas o tercetos (no son, por tanto, silvas métricas) según el modelo de las "Selve d'amore" de Lorenzo de Medicis [...]. Se trata, en pocas palabras, de poemas que combinan un primer objetivo (la descripción de la naturaleza) con la narración o dramatización de motivos fabulosos o mitológicos. Su función en el panorama de la silva española parece haber sido la de engarce entre el modelo estaciano de silva en lo que éste tiene de orientación hacia la écfrasis y el poema barroco (éste sí en silvas métricas) de los ciclos naturales tal como lo apunta Góngora en sus Soledades [...]» ${ }^{17}$. Igualmente P. Jauralde Pou vuelve a incidir en el entronque con las Soledades gongorinas, matizando que especialmente «las de Gutierre Lobo, Arjona, Juan Montero, Gregorio Morillo y Agustín de Tejada respiran el ambiente de las Soledades» ${ }^{18}$. Como afirma I. Osuna, parece definitivo el acuerdo en situar estas composiciones en «la trayectoria que va desde la silva estaciana a la silva métrica española: variedad, desorden, descriptivismo, juego elegante $[\ldots] \gg^{19}$.

14 E. Asensio, «Un Quevedo incógnito. Las “silvas”», pág. 23.

15 E. Orozco, Introducción a Góngora, Barcelona, Crítica, 1984, pág. 256.

16 A. Egido, «La silva en la poesía andaluza del Barroco», págs. 27-28.

17 J. Montero Delgado y P. Ruiz Pérez, («La silva entre el metro y el género», en B. López Bueno (ed.), La silva. I Encuentro Internacional sobre poesía del Siglo de Oro, pág. 29.

18 P. Jauralde Pou, «Las silvas de Quevedo», loc. cit., pág. 170.

19 I. Osuna, Poética silva. Un manuscrito granadino del Siglo de Oro, vol. I., pág. 28, nota 54. 
Por otra parte, el marco cosmogónico de las primeras octavas - no presente en las otras tres silvas dedicadas a los elementos - ha llevado al encuadre de la «Silva al elemento del aire» dentro de los poemas de creación del mundo. J. Lara Garrido estudia los fundamentos filosófico-teóricos de estos poemas barrocos en torno a tres ejes fundamentales: la filosofía platónica, las Metamorfosis ovidianas y la tradición bíblica ${ }^{20}$.

Y, por último, en cuanto a la última óptica de indagación crítica, en la misma línea propuesta por Emilio Orozco y a partir los planteamientos trazados por Aurora Egido, Joaquín Roses ha profundizado en las relaciones entre los poemas cíclicos dedicados a los elementos en la Poética silva y las Soledades gongorinas ${ }^{21}$, desde un análisis que va de las premisas histórico-filosóficas a la práctica literaria, estableciendo la corroboración del sistema conceptual de los cuatro elementos en estos poemas cíclicos. Siguiendo de cerca las teorías de R. Jammes sobre el contenido narrativo de las Soledades y su ideación como tetralogía - con la dimensión alegórica, simbólica y filosófica que tal entramado arrastra - , Roses ha profundizado en las relaciones entre estos cuatro poemas mencionados y las Soledades. Tras un exhaustivo recorrido por los planteamientos filosóficos en torno a los cuatro constituyentes básicos del universo, desde los presocráticos y los pensadores griegos y latinos hasta los tratadistas medievales y tratados filográficos del Renacimiento y siglo XVI, el citado estudioso perfila el entramado teórico-filosófico del sistema de los cuatro elementos sobre el que se asienta la práctica literaria de Góngora y otras que le anteceden y anticipan algunos de sus rasgos, como sucede en las composiciones que ahora revisamos.

Partiendo de estas directrices de análisis marcadas por la crítica y a partir de algunas de sus sugerencias, proponemos un nuevo ángulo de acercamiento a la «Silva al elemento del aire» de Agustín de Tejada Páez a la luz de la pluritemática manierista como estructura que integra tal variedad temática y genérica posteriormente consolidada en la poética barroca.

20 J. Lara Garrido, «La creación del mundo en la poesía barroca: de la tradición neoplatónica a la ortodoxia contrarreformista», Estudios sobre literatura y arte dedicados al profesor Emilio Orozco Díaz, Universidad de Granada, 1979, vol. II, págs. 241-262. Véase también al respecto del mismo crítico, «Sobre la imitatio amplificativa manierista. Metamorfosis de un motivo poético: la rosa de los vientos», Relieves poéticos del Siglo de Oro. De los textos al contexto, Anejo XXVII de Analecta Malacitana, 1999, págs. 149-172, especialmente págs. 162-163. Es también fundamental para el estudio de este género de poemas el análisis del romance de Lope de Vega «A la creación del mundo» llevado a cabo por Aurora Egido, «Lope de Vega, Ravisio Textor y la creación del mundo como obra de arte», Fronteras de la poesía en el Barroco, Barcelona, Crítica, 1990, págs. 198-215.

21 J. Roses Lozano, «La sustancia poética del mundo: de los cuatro elementos a las Soledades», págs. 1023-1026. 


\section{Propuesta de anÁlisis: la «Silva al elemento del aire» Como compendio}

Mitopó́tico del Ciclo de los elementos en la PoÉtica SILVA

Por el manuscrito que la ha transmitido así como por el ciclo de composiciones de que forma parte, la «Silva al elemento del aire» se halla estrechamente vinculada a la práctica académica del grupo poético granadino ${ }^{22}$, cuya labor quedó recogida en la Poética silva. Así pues, un primer factor a calibrar es su ideación como ejercicio académico, lo que ha determinado, en primer lugar, la temática $y$, como veremos en el caso de Tejada Páez, ha condicionado marcadamente su ideación compositiva:

la disparidad de aptitudes entre los participantes, la seriedad o frivolidad delos empeños [...] y las circunstancias que rodean tales reuniones (vinculación entre ciertos acontecimientos o personas, o relaciones entre sus componentes, por ejemplo) determinan unos resultados heterogéneos desde el punto de vista temático y estilístico ${ }^{23}$.

A pesar de la evidente contextualización académica, apenas se hallan indicios textuales en la silva de Tejada que evidencien esa condición de ejercicio de academia, excepto en los versos finales de la última octava:

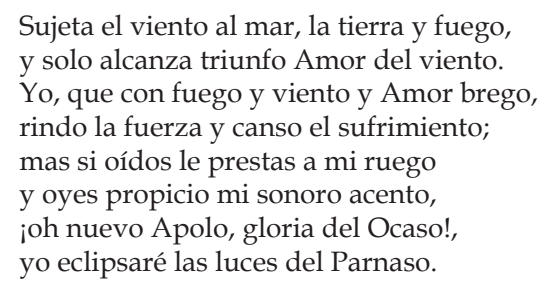

En el nivel temático, no debemos olvidar que un tema como el de los elementos estaba presente de forma frecuente en el repertorio de las sesiones académicas ${ }^{24}$. Sirva de ilustración, pues, la presencia del tema en la Academia de los Nocturnos. Willard F. King señala que entre

22 Véase el ya mencionado trabajo de J. Lara Garrido, «Los poetas de la Academia granadina (El grupo de la Poética silva)» e I. Osuna, Poesía y academia en Granada en torno a 1600: la "Poética Silva", Universidad de Sevilla, 2003, especialmente págs. 19-58. En el panorama trazado por Willard F. King de las academias españolas del XVI recoge la existencia de la academia granadina a partir de una serie de datos que figuran en textos literarios, como la epístola que Cristóbal de Mesa dirigió a Barahona de Soto: «Ya en casa de don Pedro de Granada / formaréis la poética Academia / de espíritus gentiles frecuentada» (Apud W. F. King, Prosa novelística y academias literarias en el siglo XVII, Madrid, Anejo X del Boletín de la Real Academia Española, 1963, pág. 31). Véase, asimismo, A. Egido, «Poesía de justas y academias» [1984], en Fronteras de la poesía en el barroco, Barcelona, Crítica, 1990, págs. 115-137.

23 I. Osuna, Poesía y academia, pág. 21.

24 S. López Poza habla de la relevancia del tópico de los elementos en la iconografía y su papel en la «formación académica»: «Los cuatro elementos han sido en nuestra cultura, con las estaciones y las partes del mundo, uno de los temas decorativos más empleados por los artistas, y llegó a ser un lugar común o tópico obligatorio para quienes aspiraban a una formación académica» (S. López Poza, «Los cuatro elementos en la emblemática española», J-P. Etienvre (dir.), Les Quatre Éléments dans les littératures d'Espagne (XVI e et XVII siècles), Presses de l'Université Paris-Sorbonne, 2004, págs. 295-335 (cita, pág. 295). 
las "liciones", que representan casi la única prosa creada para la academia, habían de instruir al público por su erudición y profundidad; los temas son por lo general de carácter serio (por ejemplo, "Cuál es más provechoso para la república, el estudio de las letras o el ejército de las armas"; "Discurso de las excelencias de los elementos") aunque, como es de suponer, destacan la ingeniosa sutileza y la rebuscada interpretación de las fuentes, más que la originalidad o profundidad de pensamiento ${ }^{25}$.

Así pues, en la sesión 52 celebrada el 17 de febrero de 1593 se pronuncia en la conocida Academia de los Nocturnos un «Discurso dela excellencia de los 4 elementos» ${ }^{26}$. Tal discurso contiene los puntos de referencia básicos en cualquier comento sobre los elementos: la etimología del término elemento (a partir del comentario de San Isidoro en sus Etimologías), su papel como principio básico en el origen de la materia, seguido de la exposición de sus cualidades y las relaciones con los humores corporales. El discurso se cierra con la reflexión sobre la distribución de los elementos en el orbe terrestre y las excelencias de cada uno de ellos.

Una indagación más exhaustiva nos proporcionaría, probablemente, datos de interés sobre el tema de los elementos en las sesiones de las academias áureas. No obstante, la presencia de este tema en la Academia de los Nocturnos y su consignación en las Actas de dicha Academia resulta suficientemente explicativa de papel de este motivo en estos cenáculos literarios

Esta contextualización académica resulta determinante para a configuración del texto poético, pues «el componente colectivo de la academia incide sobre distintos niveles de la producción poética. La regulación de las sesiones introduce con frecuencia factores prescriptivos orientados hacia elementos de la inventio, la métrica e incluso la elocutio» ${ }^{27}$.

Como ha comentado I. Osuna, las cuatro silvas dedicadas a los elementos comparten la libertad respecto a la materia mitológica ovidiana de la que parten. Aunque la génesis de cada una de ellas se encuentra en motivos argumentales o personajes ovidianos el desarrollo siempre es personal: respecto a la Silva al elemento del Fuego de Gutierre Lobo «salvo en lo que respecta a los nombres de dos de los protagonistas - Sílice y su hijo Pirodes - no cuenta con ningún apoyo en la tradición mitográfica» ${ }^{28}$; Pozo, por su parte, al cantar las excelencias del agua «recrea una situación de invención propia en la que Calidemo, en el transcurso de un sacrificio a

25 W. F. King, Prosa novelística y academias literarias en el siglo XVII, pág. 35.

26 Actas de la Academia de los Nocturnos, ed. de J. L. Canet, E. Rodríguez y J. L. Sirera, Edicions Alfons el Magnánim, Institució Valenciana D’Éstudis i Investigació, Diputación Provincial de Valencia, 19882000, vol. IV, 1996, págs. 107-114.

27 I. Osuna, Poesía y academia, pág. 22.

28 I. Osuna, Poética silva. Un manuscrito granadino del Siglo de Oro, vol. II, pág.117. 
Baco, proclama las excelencias del vino, asimilado al elemento del fuego, frente a los prejuicios que el agua acarrea a todo el pueblo» ${ }^{29}$; «la recreación que Pedro Rodríguez de Ardila realiza de la historia mitológica no se preocupa, sin embargo de un desarrollo cabal de la misma, retomando sólo la situación que servía de partida: la atracción que Cibeles siente por Atis» ${ }^{30}$; y, por último, en el texto que nos ocupa, Tejada incorpora de su particular acervo inventivo los amores de la Tierra y el Aire a partir de los que explica la generación de los vientos. Otro elemento retórico-estructural repetido en las cuatro composiciones es un discurso de relativa autonomía consagrado a la laus de cada elemento, junto a otros puntos de conexión entre las cuatro silvas como la «cristianización» de ciertos pasajes y la amplificación descriptiva de marcado carácter colorista y preciosista.

No obstante, a pesar de estas similitudes temáticas, estructurales y elocutivas determinadas por los preceptos académicos y el carácter cíclico, las composiciones dedicadas a los elementos gozan de total independencia y desarrollo particulares ${ }^{31}$. El primer elemento diferencial de la «Silva al elemento del aire» respecto a las composiciones restantes del ciclo ya lo señalaba Lara Garrido: «La similar estructura de las composiciones se rompe sólo en la de Tejada, quien antes de narrar la fábula del Rey Eolo introduce el proceso de la creación del mundo combinando las versiones ovidiana y bíblica» ${ }^{32}$. Aunque Lara Garrido menciona, ciertamente, que la «amistad y la admiración de Tejada por la obra de Barahona explicarían la emulación que impone la peculiaridad a esta Silva al elemento del aire» ${ }^{33}$, creemos que no sólo el propósito de emulación movería al poeta antequerano si no un proyecto de composición global e integrador que aunase y se elevara sobre las restantes propuestas. Además, no debemos olvidar que este fragmento vincula la composición tejadiana a los poemas de creación del mundo, renacentistas y barrocos, de elevado aliento épico. Junto a la novedad de la temática cosmológica, la «Silva al elemento del aire» integra los núcleos temáticos y motivos argumentales presentes en todas o en algunas de las restantes composiciones del ciclo: fábula ovidiana, inventio original, teoría de los elementos, a los que añade el topos de la tempestad y el marco o cornice amoroso. Ese marco, que remite a la experiencia amorosa del sujeto lírico, lo comparte con la «Silva al elemento del agua», frente a la dedicada a la tierra y al fuego, que no presentan esa contextualización amorosa ${ }^{34}$.

29 I. Osuna, loc. cit., pág. 129.

30 I. Osuna, loc. cit., pág. 134.

31 Así lo pone de relieve I. Osuna, Poesía y academia..., págs. 103-104.

32 J. Lara Garrido, «Un poema cosmogónico fragmentario: los "Principios del mundo" », en La poesía de Luis Barahona de Soto (Lírica y Épica del Manierismo), Diputación Provincial de Málaga, 1994, pág. 283.

33 J. Lara Garrido, loc, cit., pág. 284.

34 Ese mismo marco o cornice que encuadra la composición en la temática amorosa de expresión petrarquista se encuentra en otras composiciones de la Poética silva como las dedicadas a la Aurora, al 
Y la fórmula estructural más idónea para insertar esos diversos hilos temáticos (fabulación mitológica, marco amoroso y descripciones) la encontró el antequerano en la pluritemática manierista, un tipo de estructura que había sido cultivada en los años finales dell XVI por poetas como Góngora o Lope de Vega. La «Silva al elemento del aire» representa, frente a las demás composiciones del ciclo, un afán compendiador que encontrará su vehículo de expresión en la pluritemática manierista. Ese propósito de compendiar las posibles diversificaciones de un tema previamente dictado así como el continuo afán de experimentación cultista que caracteriza al antequerano se transparentan en la ideación compositiva de la silva ${ }^{35}$.

Sintetizando, pues, podemos concluir que, tanto en el plano temático como en el de la dispositio y elocutio, Agustín de Tejada trasciende el inicial planteamiento académico y compendia en su composición, en primer lugar, una globalidad de temas: la imitatio y la invención original, la materia ovidiana y la fabulación original, la teoría de los elementos, el topos de la tempestad, la temática amorosa; en segundo lugar, una dispositio que responde a la pluritemática manierista: esos núcleos temáticos diversos se integran en una estructura donde el tema principal se relega a segundo plano; y en tercer lugar, en el plano elocutivo despliega una serie de recursos fónicos que inciden en la sonoridad, así como un uso profuso de la bimebración y plurimembración y de la estructura diseminativo-recolectiva que definen los rasgos esenciales de la poesía manierista.

La necesidad de compendiar esta diversidad en los distintos niveles de análisis del texto literario se halla probablemente determinada por lo que M. Blanco ha llamado, a propósito del análisis de las composiciones de la Poética silva que conforman este ciclo de los elementos, «rivalité ludique»:

En ce qui concerne les quatre éléments, les poèmes ont une forte composante rhétorique, car chacun des quatre textes contient un éloge argumenté de l'élément qu'il célèbre. La série présente de ce fait la apparence d'une joute oratoire ; il s' agit pour chauqe poéte de parier pour la suprématie de l' élément qu'il a choisi de céléber, celle-ci venant se confondre avec la supériorité de l'auteur sur ses rivaux. Cependant, la règle du jeu, autrement dit le thème imposé au tournoi, exclut un véritable triomphe d'un des champions sur les autres ${ }^{36}$.

Tiempo, a la Noche y la silva al Estío.

35 Estos rasgos fueron señalados por J. Lara Garrido a propósito de la canción A la Virgen de Monteagudo en «Un audaz experimento métrico de Agustín de Tejada Páez», Revista de Estudios Antequeranos, 1 (1995), págs. 139-146, especialmente pág.143.

36 M. Blanco, «Poésie et sophistique: le cycle des quatre éléments dans la Poética silva», en J-P. Etienvre (ed.), Les Quatre Éléments dans les littératures d'Espagne (XVI et XVII siècles), Presses de l'Université Paris-Sorbonne, 2004, págs. 63-83 (cita, pág. 65). 
Dedicaremos las páginas que siguen al análisis de esos núcleos temáticos y a la técnica de imbricación tejida por la red que ofrecía la estructura desintegradora de la pluritemática manierista.

\section{Núcleos temáticos. La RED de la PluRitemÁticA MANIERISTA}

\subsection{Fábula mitológica ovidiana. Técnicas de la imitatio manierista}

Si la materia mitológica ovidiana de la «Silva al elemento del aire» de Tejada entronca con la fábula mitológica, diversos aspectos estructurales la alejan de este género. Aunque José $\mathrm{M}^{\mathrm{a}}$ de Cossío la estudió en sus Fábulas mitológicas de España, no dejó de apuntar que «se sale de la estructura corriente en las fábulas mitológicas, pese a ser su materia mítica y a traducir, o mejor parafrasear, a Ovidio en una gran parte de él ${ }^{37}$. En el mismo encuadre genérico ubica Inmaculada Osuna la silva de Tejada y las restantes que componen el ciclo: «la preponderancia del elemento mitológico y su habitual inserción dentro de un esquema narrativo - aunque, a veces, tan sólo ligeramente narrativo - aproximan estos poemas, especialmente las dos series de las silvas, al desarrollo de la fábula mitológica en la poesía del Siglo de Oro» ${ }^{38}$.

Ya se ha señalado el círculo granadino en torno a poetas como L. Barahona de Soto o G. Silvestre como uno de los focos esenciales para el desarrollo de la fábula mitológica en la poesía áurea ${ }^{39}$. Dentro de este ámbito, especialmente por influjo de Barahona de Soto, Tejada Páez no escapa al cultivo de este género de la fábula mitológica tal como se desprende de una Fábula de Vertumno y Pomona ${ }^{40}$, hoy perdida, que escribió el antequerano probablemente siguiendo de cerca la dedicada por el lucentino al mismo tema. En la mención a ella en los Discursos históricos de Antequera se registra el claro seguimiento del modelo ovidiano y la actitud del poeta hacia el dechado latino:

\footnotetext{
Y esta fábula [la de Vertumno y Pomona] la tenía compuesta en verso como la de Ero y Leandro, y Silvestre la de Narçiso [y Eco], y Montemayor y Castillejo la de Píramo y Tisbe, y don Diego de Mendoza la de Venus y Adonis, y el licenciado Soto la de Anteón, y esta propia de Bertuno con estilo tan elegante que lo tengo por insuperable, que fue atrevimiento entrar yo donde el ingenio ha puesto la mano, y Francisco de Tejada, mi padre, la de Troco y
}

37 J. M. de Cossío, Fábulas mitológicas de España, Madrid, Espasa-Calpe, 1952, pág. 280.

38 I. Osuna, Poesía y academia, pág. 116.

39 L. Barahona de Soto, Fábulas mitológicas, ed. de A. Cruz Casado, Córdoba, Ayuntamiento de Lucena, 1999 Consultado a través del Corpus Diacrónico del Español (CORDE): http:/ / corpus.rae.es/cordenet. html

40 El escaso cultivo de esta fábula en el Siglo de Oro - Martín Rodríguez de Ledesma y Marques de Palacio, junto a Barahona y Tejada (L. Barahona de Soto, Fábulas mitológicas: http://corpus.rae.es/cordenet.html) - apunta a una más que factible influencia directa del poeta lucentino en Tejada Páez. 
Salmaçes que a ninguna de éstas es inferior. Lo cual todos hicieron por aventajarse a Ovidio $[\ldots]^{41}$.

Partiendo de este encuentre genérico, vamos a analizar brevemente el diálogo que sostiene la silva tejadiana con el género de la fábula mitológica y el modelo ovidiano intentando delimitar someramente las técnicas de la imitatio.

De acuerdo a su secuenciación narrativa, en la «Silva al elemento del aire» se pueden distinguir dos núcleos claramente diferenciados. El primero de ellos — tras un marco cosmogónico inicial que abarca tres octavas - se centra en los amores de Tierra y Aire, de cuya conjunción nacen los cuatro vientos principales a los que después se añaden ocho; el segundo bloque desarrolla la fábula de Eolo, con una amplia descripción de una tempestad que sufre el dios del viento a cuya ayuda acude Júpiter otorgando desde entonces a Eolo el poder y control sobre los vientos. En torno a estos ejes narrativos se teje una trama de invención original en la que priman los cuadros descriptivos de la naturaleza:

la capacidad de aglutinar contenidos diversos y el gusto por la digresión hace que, junto con los elementos más característicos que aproximan estos poemas a la fábula mitológica, también se deje ver cierto afán erudito que atañe a diversos campos del saber [...] lo cual puede recordar vagamente en algunos momentos determinadas realizaciones de la poesía filosófica o didáctica, aunque, por supuesto, aquí tales elementos no llegan a asumir una auténtica función articuladora de los poemas en cuestión ${ }^{42}$.

Cada uno de los dos núcleos de la «Silva al elemento del aire» presenta dos modelos principales - aunque no únicos pues median otros, principalmente, la traducción de las Metamorfosis de Anguillara, además de la propia invención del poeta - de acuerdo a la técnica de la imitatio manierista. En lo hemos llamado primer núcleo (octavas 1-27) el referente indiscutible es Ovidio. El segundo bloque se consagra a la fábula de Eolo que, si bien se ampara en la mitología más corriente, sigue muy de cerca en algunos pasajes el canto I de la Eneida de Virgilio. No obstante, la técnica de la imitatio se complementa con pasajes de absoluta inventiva personal en los que el poeta re-crea o re-inventa a partir de los materiales mitológicos que le proporciona la tradición cultural. Es el caso de los amores del Aire y la Tierra para explicar la concepción de los vientos en la primera parte de la silva, y de la travesía marítima del

41 A. de Tejada Páez, Discursos históricos de Antequera, estudio y edición de A. Rallo Gruss, Diputación Provincial de Málaga, 2004, vol. I, pág. 322.

42 I. Osuna, Poesía y academia, págs. 117-118. Ahora bien, entre el modelo ovidiano y los contenidos filosóficos o didácticos media, como ha señalado Lara Garrido a propósito de la temática cosmológica de los poemas barrocos, la visión cristiana, ya sea a partir de la Biblia, en concreto del Génesis, o bien, a partir de los hexaemeron, comentarios de carácter didáctico rescatados «fragmentariamente por los humanistas, que actualizaron su función y su sentido, en especial tras las ediciones prologadas por Erasmo de los Hexaemeron de S. Ambrosio (1527) y S. Basilio (1532)» (J. Lara Garrido, «La creación del mundo en la poesía barroca: de la tradición neoplatónica a la ortodoxia contrarreformista», pág. 246). 
rey y, según señala Cossío ${ }^{43}$, de las tres octavas dedicadas a los agüeros en la fábula de Eolo.

Profundizaremos, particularmente, en las deudas con el modelo ovidiano que ofrece el libro I de las Metamorfosis, el cual opera como referente esencial de ese primer núcleo narrativo. Tejada sigue a Ovidio en el planteamiento cosmogónico de las tres octavas iniciales así como el nacimiento de los vientos y su distribución según los cuatro puntos cardinales, aunque normalmente aplicando la técnica de amplificatio sobre los hexámetros ovidianos. No obstante, quizá resulta excesiva la afirmación de Cossío ${ }^{44}$ acerca de que los versos del poeta latino sean la «falsilla» de los endecasílabos tejadianos.

Pasemosaver, pues, lasdeudasconel modeloovidianodemanera pormenorizada. La narración de Tejada abarca desde el origen del mundo hasta, podríamos decir, la separación de los continentes. El segundo núcleo narrativo, claramente diferenciado del primero, se centra en la figura de Eolo con una larga digresión en torno a una tormenta, para retomar el hilo de fabulación mitológica con la anécdota del cetro de los vientos que Júpiter otorga a Eolo y el encierro a que éstos son sometidos, todo ello encaminado a poner de relieve la superioridad del viento sobre los restantes elementos.

Las tres primeras octavas revelan deudas evidentes con el modelo de los hexámetros iniciales del libro I de las Metamorfosis que se ocupan del origen del mundo. La fórmula sintáctica de la primera octava de Tejada está tomada de los primeros versos de Ovidio que describen el caos $^{45}$ :

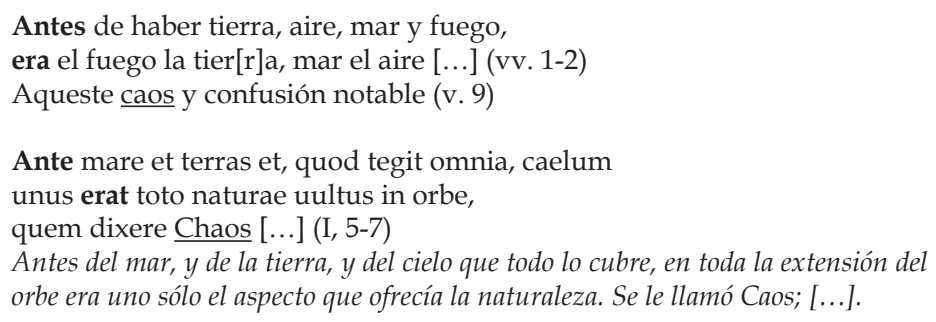

El caos inicial del universo se relata a través de la confusión de los cuatro elementos esenciales que constituyen el cosmos. Este caos es descrito por Tejada en la primera octava mediante una enumeración caótica que, en la confusión verbal, refleja esa anarquía elemental. La crítica ha subrayado insistentemente la conexión de esta

43 J. M. de Cossío, op. cit., pág. 282.

44 J. M. de Cossío, loc. cit., pág. 281.

45 Citamos en adelante por Ovidio, Metamorfosis, ed. de Antonio Ruiz de Elvira, Madrid, CSIC, 1990. 
octava con la tercera de la traducción de Andrea dell' Anguillara, mientras que el modelo ovidiano es mucho más sintético:

Antes de haber tierra, aire, mar y fuego, era el fuego la tier[r]a, mar el aire; rendía el aire al mar, la tierra al fuego, sin forma el fuego, tierra, el mar y el aire, que allí era el aire, el mar, la tierra y fuego donde era el fuego y mar, la tierra y aire; el mar y el aire y fuego eran la tierra, y había fuego en mar y aire en la tierra (vv. 1-8).
Utque erat et tellus illic et pontus et aër, sic erat instabilis tellus, innabilis unda, lucis egens aër: nulli sua forma manebat (vv. 1517)

Y por donde quiera había tierra, había también aire y agua, con lo que ni la tierra era sólida, ni valdeable el agua, ni el aire tenía luz; ningún elemento conservaba su propia figura.

El modelo ovidiano se retoma con la intervención de una fuerza superior que es la que introduce el orden en este caos inicial. En Tejada esta fuerza superior, de forma análoga a Ovidio, aparece algo desdibujada y nominada como «sumo regente». No obstante, como se ha apuntado a lo largo de la silva la narración se irá impregnando de notas cristianizadoras:

Aqueste caos y confusión notable del cielo corrigió el sumo regente: (vv. 9-10)
Hanc deus et melior litem natura diremit (v. 21) A esta contienda puso fin un dios, una naturaleza mejor.

Sigue a ello, en la segunda y tercera octava, la separación de los elementos y la consiguiente instauración del orden y armonía en el universo por medio de la intervención de ese espíritu divino. La segunda alude a la organización de los cuatro elementos, mientras que en la tercera asume protagonismo el elemento del Aire y la estrofa se cierra con la distribución de los animales de acuerdo a las características de cada uno de los elementos:

Aqueste caos y confusión notable del cielo corrigió el sumo regente: por centro colocó la tierra estable de toda aquesta máquina excelente; en torno la cercó del mar mudable, para que humedeciese su corriente de la tierra gentil las anchas salas, y encima desplegó al aire las alas.

Nam caelo terras et terris abscidit undas et liquidum spisso secreuit ab aëre caelum;quae postquam euoluit caecoque exemit aceruo, dissociata locis concordi pace ligauit. ignea conuexi uis et sine pondere caeli emicuit zumaque locum sibi fecit in arce; proximus est aër illi leuitate locoque, densior his tellus elementaque grandia traxit
Quiso que con su soplo regalado a todos los vivientes regalase y que cualquier lugar desocupado con su cuerpo diáfano ocupase; que fuese nido al escuadrón alado, que su[s] regiones húmedas cortase, y poniendo al mar pece, fiera al suelo, de aves quiso poblar al aire el velo (vv.9-24). et pressa est grauitate sua; circumfluus umor ultima possedit solidumque coërcuit orbem (vv. 2231).

La referencia al poeta de Sulmona queda patente en la distribución de los seres vivos de acuerdo al lugar que los elementos ocupan en el globo terráqueo. Sólo que Ovidio reserva la alusión a los seres vivos hasta la descripción de los cuatro vientos 
principales y su colocación según los cuatro puntos cardinales. Tejada aplica aquí, respecto al modelo ovidiano, el procedimiento de la minutio y opta por incorporar un pasaje de invención propia como es el de los amores de Tierra y Aire.

[...] y poniendo al mar pece, fiera al suelo, de aves quiso poblar al aire el velo (vv.23-24).
[...] cesserunt nitidis habitandae piscibus undae, terra feras cepit, uolucres agitabilis aër (vv. 7475).

[...] cayeron en suerte las aguas a los peces brillantes como lugar de habitación, la tierra recibió a las fieras, a las aves el movedizo aire.

El referente ovidiano deja de operar en la tercera octava, a partir de la cual se narran los amores de la Tierra y el Aire. Aunque el breve relato de estos responda a la inventiva del poeta, el modelo latino sigue funcionando en las alusiones a la destrucción y la discordia entre los vientos nacidos de tal enlace, como se observa en las octavas 12-14:

His quoque non passim mundi fabricador habendum
aëra permisit; uix nunc obsistitur illis,
cum sua quisque regant diverso flamina tractu.
quin lanient mundum: tanta est discordia fratum (vv. 57-60).

Tampoco a los vientos concedió el artífice del mundo el libre uso del aire; aun ahora es difícil impedirles que destrocen el mundo, a pesar de que cada uno dirige sus soplos en regiones separadas: tan grande es la discordia entre los hermanos.

Aunque para el nombre de los vientos el antequerano no mantiene la nominación de las Metamorfosis - prefiere Euro, Favonio, Norte y Austro, donde Ovidio escogía nombres griegos para los tres primeros excepto para el último: Euro, Céfiro, Bóreas, Austro - , la descripción de su separación siguiendo los cuatro puntos cardinales sí se atiene al relato del poeta sulmonense ${ }^{46}$, aunque siempre aplicando la amplificatio, pues la descripción de cada una de las zonas geográficas y puntos cardinales ocupados por cada viento abarca, de media, una octava en la silva frente a los dos versos de las Metamorfosis. Se mantiene asímismo el mismo orden enumerativo de Ovidio: Euro, Céfiro ( Favonio), Norte (Bóreas) y Austro:

[...]A Euro puso donde refulgente al mundo nueva luz del sol apunta y do primero la rosada Aurora las nubes de oro puro orla y colora. Al favorable Céfiro asentólo donde Venus, la estrella vespertina, se ve lucir cuando en el mar Apolo los cabellos lucíferos inclina, do acaba de enlutar la noche al polo y con húmeda escarcha y cristalina mojar la tierra y con su escura rueda dejarla del trabajo libre y queda.

Al Norte puso donde los Triones

de hielo cubren a la zona helada, cobijando las árticas regiones de una perpetua nieve condensada, donde muestran las Osas sus faiciones a la Escitia, del bárbaro pisada, y gusta hielo frío y blanca nieve cuando de Batro la corriente bebe.

46 Veáse J. Lara Garrido, «Sobre la imitatio amplificativa manierista. Metamorfosis de un motivo poético: la rosa de los vientos», págs. 49-60. 
Al Austro le dio silla do menores son las sombras del sol cuando, en el cielo esparciendo los santos resplandores, en medio de su cumbre los ve el suelo, a donde abriga el Ábrego las flores con el templado y apacible vuelo y a donde el Mar del Sur perlas produce entre la nácar que en sus ondas luce (vv. 181-208)
Eurus ad Auroram Nabataeaque regna recessit Persidaque et radiis iuga subdita matutinis: (vv. 61-62)

El Euro se retiró al país de la Aurora, a los reinos nabateos, a Persia y a las cimas bañadas por los rayos de la mañana.

vesper et occiduo quae litora sole tepescunt proxima sunt Zephiro; [...] (vv. 63-64)

El Occidente y las playas que se entibian por el sol poniente son vecinos del Zéfiro.

[...] Scythiam Septemque Triones horrifer inuasit Boreas; [...] (vv. 64-65)

El espantoso Bóreas ocupó la Escitia y los Siete Triones;

[...] contraria tellus nubidus adsiduis pluuioque madescit ab Austro (vv. 65-66).

La parte opuesta de la tierra se humedece con las constantes nubes que produce el lluvioso Austro.

En la fábula de Eolo constatamos el mismo procedimiento que combina la invención propia con pasajes que recrean un modelo clásico esencial, en este caso el canto I de la Eneida. El viaje de Eolo parece ser innovación introducida por Tejada, como expone Cossío, pero quizá no resulte acertada la invención que éste atribuye poeta antequerano acerca de las tres octavas dedicadas a los agüeros. Probablemente éstas resultado de la contaminación de variados referentes de la épica greco-latina, principalmente la Farsalia de Lucano. Para la narración de la tempestad ${ }^{47}$ así como la intervención de Jove para serenar los vientos y el posterior encierro de éstos bajo el cetro de Eolo se ciñe, nuevamente, al canto I de la Eneida. J. M. Cossío ${ }^{48}$ insiste en el referente virgiliano para la descripción de la gruta en que son encerrados los vientos y para el efecto de la tempestad sobre las naves de Eolo, paralela a la sufrida por la escuadra de Eneas.

Así, pues, Tejada polariza la narración de la «Silva al elemento del aire» en torno a los dos modelos clásicos esenciales de Ovidio y Virgilio - con otras mediaciones, en el caso de Ovidio la traducción de las Metamorfosis de Andrea dell'Anguillara, y en el topos de la tempestad algunas de sus realizaciones clásicas de mayor suerte posterior - recreándolos fielmente en unas ocasiones y en otras abriendo paso a pasajes de invención original en los que despliega un uso reiterado de la técnica de la amplificatio manierista respecto a los dechados grecolatinos.

47 Para las fuentes clásicas del motivo de la tempestad véase V. Cristóbal, «Tempestades épicas», Cuadernos de investigación filológica, 14 (1988), págs. 125-148.

48 J. M. de Cossío, op. cit., pág. 283. 


\subsection{La amplificación descriptiva. En el camino hacia el poema descriptivo barroco. Visión de la Naturaleza en la «Silva al elemento del aire»}

La técnica de amplificatio aplicada sobre los distintos modelos clásicos está orientada en la «Silva al elemento del aire» de Tejada Páez hacia la descripción de la Naturaleza en sentido amplio, bien como realidad natural, bien en su interpretación mitológica. Ya J. Lara Garrido subrayaba que la imitatio amplificativa practicada por Tejada en la «Silva al elemento del aire» era de signo mitológico, de la que el ejemplo más claro es la amplificación, por el procedimiento de la perífrasis, de la distribución de los vientos en función de los cuatro puntos cardinales (vv. 181-208) ${ }^{49}$, como yahemos tenido ocasión de señalar.

El elemento narrativo o argumental de la «Silva al elemento del aire» es mítico y ovididiano en sus constituyentes principales. Ahora bien, Tejada se sirve de este hilo para engarzar de forma continuada y sistemática, a lo largo de 480 versos, cuadros descriptivos de variado signo. Éstos, principalmente aéreos y acuáticos, muestran una nota común: la de presentar el poder destructivo de la naturaleza a través de uno de sus elementos, el aire, al que está dedicada la composición. La visión de la naturaleza que nos ofrece la silva se recrea en la observación de lo extremado de los vientos. No obstante, en otras ocasiones se opta por presentar el contraste entre una naturaleza serena y equilibrada frente a la contemplación del poder destructor del elemento del aire, como sucede en los pasajes que recogemos a continuación. Del orden a que se somete el caos inicial y la división de los elementos resulta esta visión de la naturaleza:

[...]jugando por el mar fresca marea,

andan las varias ondas retozando

al soplo del frescor que las ondea,

o de la suerte que el Favonio blando

las hojas de los árboles menea,

que entre ondas y hojas y aire que las bate

resulta un son confuso del combate (vv. 34-40)

frente a la descripción, unas octavas después, de los efectos que la concepción de los vientos en el seno de la madre Tierra provoca en el orbe:

Del concebido humor estremecióse

y hizo blandear más de una cima

49 J. Lara Garrido, «Sobre la imitatio amplificativa manierista. Metamorfosis de un motivo poético: la rosa de los vientos», pág. 162. I. Osuna incidía en el mismo aspecto al subrayar la fidelidad del antequerano al modelo ovidiano en los vv. 181-200 en los que recrea los vv. 61-66 de las Metamorfosis y llama la atención sobre que «ni en el original latino, ni en la versión italiana mencionada [la de Anguillara], ni en las principales traducciones castellanas de entonces (realizadas respectivamente por Jorge de Bustamante, Antonio Pérez Sigler, Pedro Sánchez de Viana y Felipe Mey) hay precedentes de esta demora descriptiva» (I. Osuna, Poética silva. Un manuscrito granadino del Siglo de Oro, vol. II, págs. 124-125). 


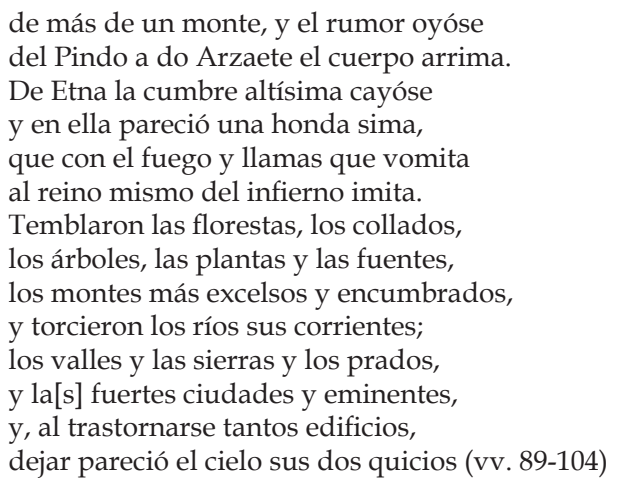

En otras ocasiones, las descripciones se ciñen a una estricta ambientación mitológica y se impregnan de color y matices preciosistas, como la pintura de Júpiter en su carro serenando el mar después de la tempestad (vv. 161-384). El hilo argumental, entonces, sirve de engarce a una serie de cuadros descriptivos amplios y reiterados en los que el relato mitológico acaba por subordinarse a la visión y sentimiento de la naturaleza que se va revelando a través de las descripciones. El relato mítico, al que el autor incorpora su inventiva propia, queda reducido a la narración escueta de la creación del mundo y la generación de los doce vientos principales, que se completará con la digresión de la fábula de Eolo, quien tras sufrir una tormenta, es encargado del control de los vientos para devolver al mundo la armonía perdida. La cabida que el procedimiento descriptivo tiene en esta silva y en las restantes que componen el ciclo confirma, una vez más, el papel de los poetas granadinos o antequerano-granadinos en el arranque de la poesía descriptiva barroca.

En definitiva, podemos concluir que el referente ovidiano, ya sea filtrado por los hexaemerones o por la tradición bíblica medieval, o bien, simplemente, adaptado a los marcos de la ortodoxia católica, se amplifica atendiendo al procedimiento que J. Lara Garrido denominó imitación amplificativa manierista. El leve hilo narrativo en la «Silva al elemento del aire» serpentea en continuos remansos descriptivos en los que el poeta se complace en ofrecer una visión de la naturaleza que anticipa la que se forjará en la lírica barroca.

\subsection{La Naturaleza en sus constituyentes elementales: entre las cosmogonías y la teoría de los elementos. Tratamiento del elemento del aire}

El relato cosmogónico de la «Silva al elemento del aire», tal como hemos indicado, sigue la versión ovidiana en sus aspectos esenciales: del Caos surge un orden universal gracias a la disociación de los elementos y el posterior equilibro en 
sus relaciones dialécticas a partir del principio de la complementariedad, todo ello propiciado por la intervención de un Dios (v. 10) en función demiúrgica del que queda sin definir exactamente su naturaleza. El antequerano se ciñe a la versión de las Metamorfosis en la disociación de los elementos a partir de la que se introduce el orden en el Caos primigénio mediante la ley platónica de la «discordia-concors» que determinará la armonía del mundo. El uso por parte de Tejada de la traducción de Andrea dell' Anguillara, perfecta versión sincrética de la ley platónica de la «discordiaconcors», sitúa las coordenadas conceptuales ${ }^{50}$ desde las que traza la cosmogonía de la «Silva al elemento del Aire».

Unido al tema del origen del mundo aparece el de la teoría de los elementos que si bien se incluye de alguna manera en el primero, presenta ramificaciones más amplias. La doctrina de los elementos se erigió, hasta racionalismo del XVIII, en una parte sustancial del pensamiento de Occidente sobre la naturaleza, su origen y sus fundamentos de orden material. Esta teoría elemental se convirtió en principio explicativo del origen del universo y la imaginación literaria encontró en ella un venero más para convertir la naturaleza en sustancia y materia poética. Esta doctrina parte de una fundamentación filosófica anclada en el pensamiento de los primeros filósofos griegos Platón y Aristóteles, que heredarán, posteriormente, los pensadores romanos, a la vez que se expandió a otros ámbitos del conocimiento como la medicina precientífica y la literatura. Su versatilidad la hace capaz de sintetizarse con el pensamiento cristiano recogido en el Génesis y se puede rastrear en la obra de los Padres de la Iglesia como san Agustín, san Isidoro de Sevilla o santo Tomás.

En cuanto al estado de la cuestión bibliográfico ${ }^{51}$, el estudio de los elementos ha sido abordado desde la perspectiva antropológica hasta la crítica literaria. Son canónicos los estudios que $\mathrm{G}$. Bachelard ${ }^{52}$ ha dedicado a cada uno de los elementos fijando sus respectivas poéticas, así como contamos con una serie de trabajos centrados en la obra de autores concretos desde la Antigüedad hasta la literatura contemporánea ${ }^{53}$. En la literatura del Siglo de Oro es la figura de Calderón la que más interés ha suscitado al respecto $^{54}$.

50 Como ha puesto de relieve J. Lara Garrido («La creación del mundo en la poesía barroca: de la tradición neoplatónica a la ortodoxia contrarreformista», pág. 253-258) la mayoría de los poemas barrocos sobre la creación del mundo se atienen a la versión sincrética ovidiano-bíblica sintetizada en la traducción de Anguillara (págs. 244-245, 248 y 249).

51 La bibliografía al respecto aparecerá citada al hilo de la argumentación.

52 Nos interesa especialmente el dedicado al aire: El aire y los sueños: ensayos sobre la imaginación del movimiento, Madrid, Fondo de Cultura Económica, 1993.

53 Entre los dedicados a poetas del siglo XX destacamos el llevado a cabo por M. Alvar, «Los cuatro elementos en la obra de García Lorca», Símbolos y mitos, Madrid, CSIC, 1990, págs. 187-213.

54 Los dos trabajos sobre el dramaturgo barroco son los de E. M. Wilson, «The four elements in the 
La exposición que ofrece Tejada en su silva sobre el aire se adecua a la argumentación tradicional sobre este elemento ${ }^{55}$, aunque siempre en conexión con los tres restantes a partir de esa concepción de la Naturaleza en sus cuatro constituyentes elementales. Tanto las primeras mitologías como la religión cristiana modelaron una idea de la naturaleza y de los elementos que la constituyen desde una doble faz: la creación y la vivificación pero, también, su poder destructor. Del aire presenta Tejada, asimismo, esa dualidad: por un lado su caracterización positiva, especialmente, en la laus proferida por el mismo para persuadir a la Tierra de su amor, y, por otro, sus efectos destructores ${ }^{56}$, en los que se focaliza el interés descriptivo a lo largo de la silva. Los filósofos presocráticos se afanaron en determinar cuál de las cuatro sustancias básicas - tierra, agua, aire y fuego - era el principio básico de constitución del cosmos. Fue Anaxímenes el que estableció como sustancia elemental para la composición del cosmos el aire argumentando que en él todo se disuelve y también todo se genera ${ }^{57}$.

Tejada se adecua sin mayores pretensiones de profundidad a la doctrina aristotélica sobre los cuatro elementos. El cosmos se compone de cuatro sustancias en estado puro, las cuales se estratifican de la siguiente manera: la tierra, el elemento más pesado, se sitúa en una capa inferior, el agua en una zona intermedia, sigue en una zona superior el aire, y en la capa superior el fuego. Junto a los elementos sitúa cuatro cualidades que aparecen en éstos en variada combinatoria: la tierra es fría y seca, el agua fría y húmeda, el aire caliente y húmedo y el fuego caliente y seco.

La literatura latina, como hemos visto en Ovidio, adapta la doctrina de los elementos, y la literatura cristiana medieval sintetiza la teoría clásica de estas sustancias fundamentales con el Génesis. En este punto de confluencia se enmarcan las reescrituras áureas. San Agustín asoció cada elemento a cada uno de los sentidos. Al aire corresponde el oído tal como la silva pone de relieve en el plano fónico subrayando una serie de recursos de armonía imitativa y de asprezza que constituyen, sin lugar a

imagery of Calderón», Modern Languague Review, 31 (1936), págs. 34-47, y A. A. Parker, Los autos sacramentales de Calderón, trad. de F. García Sarriá, Barcelona, Ariel, 1983 (1943 $3^{\left.1^{\circ} \text { ed. }\right) . ~ S o b r e ~ o t r o s ~ a u t o r e s ~ a ́ u r e o s ~}$ ya hemos citado el dedicado a Góngora por J. Roses. Han recibido atención a este respecto P: Espinosa y el Conde de Villamediana: A. Therry «Pedro Espinosa and the Praise of Creation», Bulletin of Hispanic Studies, XXXVIII (1961), págs. 127-144; y F. A. De Armas, «The Tour Elements: Key to an Interpretation of Villamediana's Sonnets», Hispanic Journal, IV, 1982, págs. 61-79.

55 Para esta exposición seguimos de cerca el artículo de J. Salazar Rincón, «Entre la ciencia y el sueño: notas sobre la fortuna de los cuatro elementos en las letras españolas», Revista de Literatura, 128 (2002), págs. 319-364.

56 En el Génesis $(2,7)$ se da cuenta de su hálito benéfico y en el Eclesiástico $(43,14-22)$ de su poder aniquilador.

57 G. S. Kira y J. E. Raven, Los filósofos presocráticos. Historia crítica con selección de textos, Madrid, Gredos, 1969, vol. I, págs. 134 y 136. 
dudas, uno de los mayores aciertos de la composición ${ }^{58}$. Por otra parte en el discurso laudatorio al aire Tejada actualiza una idea ya subrayada por santo Tomás, la de la sutilidad, que lo hace elemento más excelente junto al fuego, en detrimento de la tierra y el agua, puesto que los dos primeros están más cerca de la esfera celestial y los dos últimos más apegados a lo terrestre. Junto a ello, la doctrina de los cuatro elementos ya sirvió de base a una medicina antigua que asocia los elementos y sus cualidades a los cuatro humores del cuerpo, y, en la Edad Media, desarrolló a una psicología precientífica que asocia los cuatro elementos a cuatro caracteres, virtudes y vicios. $\mathrm{Al}$ aire corresponde la calidad sanguínea, que arrastra consigo la ira y el arrebatamiento. Todo ello, posiblemente, late en el fondo de la concepción del aire que presenta Tejada en su silva.

El Renacimiento integra en su espíritu científico y humanista la doctrina de los elementos. La filosofía neoplatónica desarrolla un sistema de correspondencias que se basa en la combinación armónica de los cuatro elementos regidos por la ley universal del amor. El número cuatro se impregna de una aureola mágica a la que invitan los cuatro elementos, sus cuatro cualidades, los cuatro humores, las cuatro edades y las cuatro estaciones. Los tratados doctrinales insisten en una idea que Tejada aprovechará para proclamar la supremacía del aire: la excelencia del elemento reside en su mayor apartamiento de la materialidad terrestre y su acercamiento a componentes más espirituales.

En los siglos XVI y XVII la teoría de los cuatro elementos se incorpora a la poesía, especialmente en textos que describen la creación. En la imaginería tanto renacentista como barroca los elementos se van a dotar de variada simbología que la práctica poética irá consolidando. Dentro de este sistema simbólico el que aparece adecuarse más al texto tejadiano es el de los elementos como emblema de la inestabilidad y de la violencia con que actúa la naturaleza, adversa al hombre. No obstante, ese poder destructor de los elementos revela, al final de la silva, una funcionalidad distinta: la de la comparación de ese desmedido poder de naturaleza con la fuerza del amor. La

58 Así fue notado por D. Cotta, «La "qualitas sonorum" como recurso expresivo en la poesía de Agustín de Tejada Páez», Canente, 1 (2001), págs. 183-234: «En una fábula mitológica como la del Aire, que básicamente versa sobre la fiereza y el poder de los vientos primitivos, están dispersos aquí y allá los sonidos ásperos, entre ellos la $R$, como en este verso tan violento fonética y semánticamente: "Rompió la tierra el mar y su ribera"» (pág. 193). En algunas estrofas de la silva la intensificación de recursos sonoros resulta realmente notable como subrayaba Cotta respecto a la octava que ocupa los versos 457-464: «Multitud de recursos fónicos se dan cita en la presente octava: la frecuencia de vibrantes, ya múltiples ("rompen"), ya trabadas con $t$ ("postran"); la reiteración de la nasal implosiva ante oclusivas dentales ("postran"), velares ("encostran") y bilabiales ("zumba"); el efectos de los esdrújulos ("cálidos"); los seis finales de verso consonánticos; y lo que interesa: la abundancia de sibilantes en posición implosiva, ya por formar parte de la sílaba ("descostran") o de la palabra ("los vientos fríos"). El resultado de todo ello es una estrofa que podría calificarse de aspérrima y en la que todos los fonemas mencionados formarían una onomatopeya extendida» (pág. 205). 
capacidad devastadora del aire, puesta de relieve a lo largo de toda la composición, se ve superada por una nueva fuerza introducida por el poeta en la organización cósmica, el Amor.

5. El MARCo AMOROSO: la FAbUla MitológicA, LA DESCRIPCión DE LA NATURALEZA Y LA TEORÍA DE LOS ELEMENTOS EN LA PLURITEMÁTICA MANIERISTA.

\subsection{La pluritemática manierista}

Las dos secuencias narrativas principales - la fábula ovidiana de los amores de Tierra y Aire y la fábula del dios Eolo - y los diversos motivos temáticos - descriptio de la naturaleza, el topos de la tempestad y la teoría de los elementos - componen la red de la pluritemática manierista en la «Silva al elemento del aire» de Tejada Páez. La jerarquía establecida en los distintos niveles textuales (temático, enunciativo y pragmático) se quiebra en la octava final. La introducción de un «quinto elemento», el Amor, la presencia del sujeto lírico en primera persona frente al modo enunciativo dominantem en tercera persona tanto en las secuencias narrativas como descriptivas, así como la contextualización pragmática introducida por el enunciador lírico al dirigirse a un auditorio - que estimamos será el académico - reformulan las pautas de lecturas hasta este momento establecidas:

Sujeta el viento al mar, la tierra y fuego,
y solo alcanza triunfo Amor del viento.
Yo, que con fuego y viento y Amor brego,
rindo la fuerza y canso el sufrimiento;
mas si oídos le prestas a mi ruego
y oyes propicio mi sonoro acento,
¡oh nuevo Apolo, gloria del Ocaso!,
yo eclipsaré las luces del Parnaso (vv. 473-480).

El protagonismo temático que adquiere el asunto amoroso a modo de cornice relega a secundario los núcleos temáticos privilegiados en extensión y jerarquía narrativas. De la comparación que se establece entre el Amor y el resto de los elementos resulta la superioridad del primero en relación a ellos y, especialmente, respecto al Aire, objeto de la laudatio de la silva. Si a lo largo de la silva se ha ensalzado el poder destructor del Aire frente a los otros tres elementos - como sentencia el v. 473: «Sujeta el viento al mar, la tierra y fuego»-, en los versos finales el Amor se revela como fuerza superior al componente elemental más poderoso, pues «sólo alcanza triunfo Amor del viento». Paralelamente, se introduce una instancia discursiva hasta ahora ausente, el sujeto lírico en primera persona que encarna el sentimiento amoroso: «Yo, que con fuego y viento y Amor brego, / rindo la fuerza y canso el sufrimiento». Su 
presencia se hace reiterada en esta octava final mediante el pronombre personal y los posesivos correspondientes a esa primera persona («yo», vv. 475 y 480).

Esta traslación del tema principal amoroso al final así como la reducción de su desarrollo a cuatro versos frente al protagonismo de motivos temáticamente secundarios nos sitúa ante un tipo de estructura que responde a los rasgos de la pluritemática manierista:

el Manierismo gusta [...] no sólo de acomodar en distribución complicada sus elementos dentro del conjunto compositivo, sino en alterar la lógica y natural valoración de estos elementos desarrollando los introducidos como secundarios hasta imponerse cuantitativamente a nuestra primera visión o lectura cual si fueran los principales, objeto o asunto, del poema o el cuadro. Se crea así, un descentramiento por el coexistir, diríamos, de varios temas con una decidida estructura pluritemática $[\ldots]^{59}$.

Esta estructura manierista ha sido señalada para las fábulas mitológicas de L. Barahona de Soto dedicadas a Vertumno y Pomona, y a Acteón. Especialmente la primera fue, indudablemente, modelo esencial para la dedicada al mismo tema por Tejada y que hoy se encuentra perdida:

En este sentido creemos que la fábula [de Vertumno y Pomona] ofrece una estructura claramente manierista [...], puesto que encontramos a lo largo del texto una marcada ocultación del tema fundamental amoroso referido al poeta y una historia mitológica muy visible y más bien objetiva, en el fondo aplicada a la real o fingida situación amorosa personal, sólo explícita al principio y en algún otro lugar de la composición ${ }^{60}$.

Este tipo de organización lógico-discursiva que afecta a la dispositio quedó aquilatada en una serie de textos escritos entre las dos últimas décadas del XVI y la primera del XVII - principalmente sonetos amorosos - por los poetas ${ }^{61}$ más significativos del momento: Góngora, Lope, Cervantes, o, entre los italianos, L. Groto. E. Orozco planteaba la cuestión del pluritematismo como marca de la estética manierista y la caracterizaba en relación a los principios estructurales de la lírica barroca ${ }^{62}$. A partir

59 E. Orozco, «Estructura manierista y estructura barroca en poesía (con el comentario de unos sonetos de Góngora)», en Manierismo y Barroco, Madrid, Cátedra, 1975² ed, pág. 170.

60 L. Barahona de Soto, Fábulas mitológicas, ed. de A. Cruz Casado, Ayuntamiento de Lucena, 1999 (lo consulto a través de la Biblioteca Virtual Cervantes: www.cervantesvirtual.com/servlet/SirveObras/ 05811630990536284199079/index.htm). A semejante disposición responde la estructura de la Fábula de Acteón: «la historia mitológica, como ocurrían en el ejemplo anterior, es un recurso más que envuelve la relación amorosa personal, sólo entrevista en los versos iniciales y en diversos lugares del texto, construcción que hemos considerado de carácter manierista, como ya señalamos antes» (L. Barahona de Soto, Fábulas mitológicas).

61 El pluritematismo manierista ha sido estudiado también por E. Orozco en el Quijote, quien ha señalado la técnica de intercalación de episodios, novelas cortas, digresiones, etc. en la novela cervantina como típicamente manierista, haciéndose eco de las palabras de Cervantes cuando hablaba sobre una «escritura desatada» en «una tela de varios hermosos lazos tejida» que «da lugar a que el autor pueda mostrarse épico, lírico, trágico, cómico». (E. Orozco, Cervantes y la novela del barroco, edición, introducción y notas de J. Lara Garrido, Universidad de Granada, 1992).

$62 \mathrm{Al}$ caracterizar la poesía manierista en contraste con la barroca, E. Orozco ponía de relieve que tanto «las complicaciones constructivas, como los movimientos violentos de los lienzos manieristas y barro- 
de la fundamentación de la estructura desintegradora manierista en el Arte nuevo de hacer comedias de Lope de Vega, Orozco puntualiza que ésta «contradecía el precepto clasicista de la unidad con esta forzada estructura desintegradora, que acudía a un recurso de composición conservando el valor de las partes sin integrarlas» ${ }^{63}$, a la vez que «al racional principio de unidad que imponía la Poética, se oponía el de la variedad que en el Arte nuevo de Lope de Vega se fundamentaba en la naturaleza» ${ }^{64}$. El maestro granadino señalaba la variedad como nota anticlásica que vincula el Manierismo y el Barroco, pero con un sentido y finalidad opuestos. Frente al Barroco, el Manierismo busca «la variedad y el contraste, a veces con elementos muy distintos, pero de forma paratáctica, con un pluritematismo sostenido en una estructura desintegradora [...]» ${ }^{65}$. La complejidad de la composición es una búsqueda manierista que aspira, frente a la visión unitiva y de sentido realista del barroco, a «romper la unidad de la obra clásica desintegrando sus elementos y alterando la lógica valoración de cada uno en el conjunto, en forma que, cuantitativamente, lo secundario a veces se ofrece como esencial y viceversa $[\ldots] \gg^{66}$.

Al hilo de las observaciones de E. Orozco debemos subrayar que la preocupación por el artificio compositivo responde a una actitud intelectualizante ${ }^{67}$ propia del clasicismo manierista. A esta actitud se asocian otros dos presupuestos: el deleite del lector al que aspira la diversidad temática, en primer lugar, y apunta, en segundo

cos, no se pueden considerar como iguales; en realidad por su sentido, pese a la apariencia, representan lo contrario. [...] Esa alteración se produce en el cuadro manierista como algo que le sobreviene a los cuerpos y formas desde fuera, como algo racional, previo e impuesto» (E. Orozco, Manierismo y Barroco, pág. 42), frente al barroco, que no plasma otra cosa que la pasión del movimiento, la irrefrenable captación de un instante. Establece, pues, una distinción desde el punto de vista estructural y estilístico: sentido unitivo barroco frente a desintegración manierista; esquemas intelectualizados previos en el manierismo y penetración del sentido realista en el barroco. En sus propias palabras, en el caso del Barroco «esta variedad supone la integración de los distintos elementos en un todo [...]; pero variedad determinada o reflejada de la misma realidad y no impuesta por la mente del artista. Hay complicación, y extremada, pero con un principio de subordinación a un motivo o intención central. No ocurre así con la complejidad y complicación manierista que no arranca de la realidad ni aún del natural desarrollo de la obra, sino que le es impuesta en un exceso de formalismo como molde o esquema» (E. Orozco, «Estructura manierista y estructura barroca en poesía (con el comentario de unos sonetos de Góngora», pág. 166). Respecto a lo que ahora nos interesa «el fenómeno manierista no es, pues, un fenómeno que arranque de lo humano todo; por esto, en sus esenciales expresiones no tiende tampoco a actuar en el espíritu a través de los sentidos [...]; tiende a actuar sobre el intelecto, a recrear racionalmente; no se dirige a la vida en su integridad» (E. Orozco, Manierismo y Barroco, págs. 43-44).

63 E. Orozco, «Variedad y pluritematismo. Estructura desintegradora manierista y unitiva barroca», en Introducción al Barroco, Universidad de Granada, 1988, 2 vols., vol. I, págs. 113-128 (cita, pág. 126)

64 E. Orozco, Introducción al Barroco, vol. I, pág. 113.

65 E. Orozco, loc. cit., pág. 114.

66 E. Orozco, loc. cit., pág. 115.

67 Así lo establece Orozco en distintos lugares: «La complicación manierista procede en general de unos determinantes teóricos intelectualistas, normativos, que supone la reglamentación y esquema previo al que ha de someterse la composición de la obra [...]» (E. Orozco, Cervantes y la novela del barroco, pág. 219). 
lugar, al afán erudito y alarde intelectualista ${ }^{68}$. Principalmente los poetas andaluces y, entre ellos, de forma destacada F. de Herrera encarnaban estos presupuestos ${ }^{69}$ :

Este arte intelectualista normativo de Herrera, preocupado por el artificio compositivo, por el escogimiento de palabras - y en general por los nuevos y cultos modos de expresióny atento a los buenos modelos y al entendimiento, no sólo atrajo a Góngora, sino que lanzó a la emulación del mismo y de los petrarquistas toscanos en quienes más lucían las complicaciones y artificios manieristas, como los sonetos pluritemáticos y plurimembres llamados raportées en Francia; pero su atractivo por lo sensorial y su impetuosidad vital le impulsaron progresivamente a prescindir de moldes, normas, modelos y limitaciones ${ }^{70}$.

Este tipo de estructura pluritemática, junto al alarde técnico y afán erudito inherentes a todo ejercicio de academia, servía a Tejada para su proyecto aglutinador de dar cabida en la silva a los más variados elementos en una propuesta poética abarcadora que englobase el tema preceptivo de la academia (la laudatio al aire) y sus posibles ramificaciones: la temática cosmogónica, la inventio original sobre la fábula mitológica ovidiana, la temática amorosa y el aliento épico que impregna la recreación del tópico de la tempestad.

\subsection{Motivos de la pluritemática manierista: la fábula mitológica, la descripción de la Naturaleza y los elementos}

En este tipo de organización compositiva manierista, de la que hemos esbozado una caracterización bastante pausada, los subtemas suelen ser recurrentes de tal manera que se puede establecer una suerte de codificación temática a partir de los textos que se atienen a tal estructura. Los temas suelen ser principalmente dos: la fábula mitológica - o motivos de ella derivados-, principalmente procedente de las Metamorfosis, y la descripción de la Naturaleza, habitualmente en sus manifestaciones más adversas cuyos efectos catastróficos funcionan como paradigmas comparativos de aquellos causados por el sentimiento amoroso. Junto a estos dos subtemas, los cuatro elementos constituyen un motivo asociado a la expresión amorosa en el código petrarquista, pues como recordaba Orozco es «en el petrarquismo donde cristalizan casi todas las estructuras manieristas en la poesía amorosa ${ }^{71}$. Estos tres motivos se contrapuntean

68 «La correspondencia de rasgos entre las formas artísticas, las poéticas e incluso las de erudición, así como en el espíritu que las informa y los fundamentos doctrinales que las alientan, y a la vez las condicionan, demuestran claro cómo el Manierismo en Andalucía se manifiesta con pleno carácter de estilo» (E. Orozco, «El manierismo y la teoría normativa de Herrera», en Cervantes y la novela del barroco, págs. 363-395 (cita, pág. 373).

69 «Y en Herrera encontramos también todas las normas y recomendaciones intelectualistas respecto a la composición, aspecto esencial de la concepción manierista en la literatura y pintura, buscando la reunión de varios miembros formando un cuerpo» (E. Orozco, «El manierismo y la teoría normativa de Herrera», pág. 377).

70 E. Orozco, «El manierismo y la teoría normativa de Herrera», pág. 378.

71 E. Orozco, «Estructura manierista y estructura barroca en poesía (con el comentario de unos sonetos de Góngora», pág. 177. 
con la temática amorosa en una estructura que privilegia discursivamente lo que en el nivel temático queda relegado a un lugar secundario.

Conviene revisar, entonces, la práctica textual que ha dado pie a la acuñación de este tipo de estructura pluritemática manierista. En la compilación poética más significativa del manierismo, las Flores de poetas ilustres de Pedro Espinosa de 1605, podemos rastrear toda una serie de

poemas pluritemáticos, es decir, organizados en dos o más materias, una de las cuales es la del amor; las otras actúan o bien como términos de comparación con el tema amoroso, o bien como introducción, a veces más larga que el tema central (sobre todo en los sonetos) ${ }^{72}$.

Es el caso de sonetos como «Llevó los pámpanos otubre [sic]» (3) de L. L. de Argensola, «Cubierto estaba el sol de un negro velo» (118) de Luis Martín de la Plaza, «La luz mirando y con la luz más ciego» (26) de Juan de Valdés y Meléndez, y «Si puedo de Anfión el dulce canto» (56) de Juan de Arguijo.

Junto a la antología de Espinosa, otro jalón inexcusable en el repaso a textos que ostentan este tipo de estructura lo constituye la poesía gongorina. Orozco estudió ampliamente este aspecto de la pluritemática en los sonetos del cordobés. Hay que tener en cuenta que la mayoría de ellos datan de fecha anterior a 1600 y una cuarta parte fueron escritos en $1582^{73}$, cronología que enmarca la vigencia de este tipo de experimentación manierista y que nos sitúa en una fecha cercana, casi paralela a la redacción de la silva de Tejada. En estos primeros sonetos gongorinos hay que considerar la imitación italiana $^{74}$ - especialmente de L. Groto (1541-1585), al que atenderemos después, dechado fundamental caracterizado por extremar las artificiosidades manieristas - , la impronta petrarquista y la huella de Herrera ${ }^{75}$. La caracterización que Orozco aplicaba en dos párrafos ${ }^{76}$ a Góngora como poeta «entre el manierismo y el barroco» sirve de planteamiento genérico que sitúa las coordenadas epocales en que se fijan las pautas estéticas y formales que comparten este ramillete de textos que estamos analizando:

72 G. Garrote Bernal, «Barahona de Soto en las Flores de poetas ilustres de Espinosa», Málaga, Anejo XLIII de Analecta Malacitana, 2002, pág. 56.

73 E. Orozco, Los sonetos de Góngora (antología comentada), edición e introducción de José Lara Garrido, Diputación de Córdoba, 2002, pág. 15.

74 Ya D. Alonso puso de relieve que «la mayor ambición estética del Góngora joven es petrarquista. Algunos tipos especiales no cabe duda de que llegaron a través de la obra de otros petrarquistas italianos» («Notas sobre el italianismo de Góngora», Obras completas, vol. VI, Madrid, Gredos, 1982, pág. 348).

75 Matizaba, en cuanto a posibles modelos, E. Orozco que «Góngora, con el grupo de poetas antequerano-granadinos coinciden $-\mathrm{y}$ mutuamente se influyen - en tendencias y modelos. Influjos de dicha procedencia italiana y especialmente del Tasso - paralelo a nuestro Herrera en su significación de tránsito del Manierismo al Barroco - los seguiremos encontrando en los primeros sonetos del cordobés» (E. Orozco, Los sonetos de Góngora (antología comentada), pág. 50).

76 Citados por J. Lara Garrido en «Los sonetos de Góngora de Emilio Orozco Díaz. Razones para el rescate de una inédita antología comentada», en E. Orozco, Los sonetos de Góngora (Antología comentada), pág. 22. 
El ideal manierista suponía una postura intelectualista orientada por la imitación de los clásicos y, en consecuencia, de inspiración en el arte y no en la vida. Busca lo extraño, difícil y complicado; pero complicación impuesta, de esquema previo, que canaliza la expresión en complejas estructuras sintácticas y métricas contrarias a lo lógico y natural. Así se dará el gusto por la composición pluritemática, que muchas veces destaca, formalmente, el tema secundario como lo principal, dejando reducido o relegado el fundamental, y las construcciones correlativas, que, apoyadas en la plurimembración métrica ofrece sorprendentes desarrollos, diríamos verticalmente, de correspondencia, de temas u objetos que se asocian o contrastan con efecto artificioso sorprendente. Así luce en los sonetos de Góngora ${ }^{77}$.

Así pues, repasaremos seguidamente junto a algunos de los ya señalados, textos de F. de Herrera, Lope de Vega y Góngora, principalmente, determinados por esta estructura manierista y organizados en torno a esos tres núcleos argumentales referidos. Con ello caracterizaremos esta práctica poética, que se halla en la base de la silva de Tejada, con el objeto de ecidriñar la técnica de entrelazamiento de estos motivos temáticos en la red de tal estructura compositiva manierista.

\section{Descripción de la naturaleza}

El núcleo argumental de mayor presencia en la pluritemática manierista es el de la descripción de la naturaleza incidiendo, habitualmente, en lo que ésta tiene de desmesurada y sublime en sus manifestaciones más extremas, como inundaciones, tempestades u otras catástrofes naturales. Estos fenómenos aparecen como referente comparativo de los efectos del amor, que sirve de tema-marco.

El gusto de Tejada Páez por estas estructuras bitématicas queda fijado en el soneto publicado por P. Espinosa en las Flores de poetas ilustres (1605):

Despoja el cierzo al erizado suelo

del verde y hermosísimo atavío;

detiene el curso el presuroso río

porque a sus sueltas aguas prende el yelo.

El cielo, vuelto en nubes, muestra el velo;

el viento sopla proceloso y frío;

el mar, bramando con hinchado brío, corrientes montes de agua sube al cielo.

Asoma la florida primavera

y el campo, antes desnudo, adorna y viste,

suelta las aguas, da templanza al viento,

aclara el cielo, aplaca la mar fiera,

que al fin tiene mudanza el tiempo triste

y espero la tendrá mi gran tormento ${ }^{78}$.

77 E. Orozco, Introducción al Barroco, vol. II, pág. 79.

78 P. Espinosa, Flores de poetas ilustres, ed. de B. Molina Huete, Sevilla, Fundación José Manuel Lara, 2005, pág. 103. 
Este soneto revela esa misma estructura manierista con la preterición del tema principal a los dos últimos versos así como testimonia el demorado desligue descriptivo en el efecto de los vientos en los vv. 6-8, desarrollado ampliamente en la silva y en otras composiciones del antequerano.

Igualmente, otros autores del círculo antequerano, como Luis Martín de la Plaza cultivaron este tema petrarquista del poder de la dama sobre los elementos de la naturaleza:

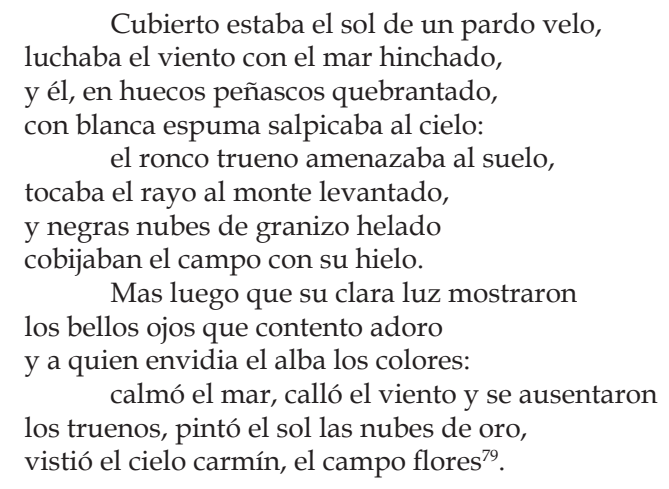

Este tipo de estructura que venimos comentando se elevó a grado de maestría en los sonetos gongorinos. De éstos atenderemos, particularmente, a aquellos en los que los temas secundarios «desplazados» a primer plano son la Naturaleza y la mitología (estos últimos los trataremos en el epígrafe siguiente). Los primeros sonetos del cordobés, escritos entre 1584 y 1588, representan la culminación de esta praxis poética definida por el pluritematismo o bitematismo con la «preterición extrema del asunto o intención fundamental» ${ }^{80}$.

A este respecto centra nuestra atención el ya mencionado soneto que empieza «Cosas, Celalba mía, he visto extrañas» ${ }^{81}$, articulado por la descripción de una catástrofe natural - el desbordamiento del Guadalquivir - mediante la que se ofrece una visión dinámica de la naturaleza la cual acaba equiparándose hiperbólicamente con el

79 L. Martín de la Plaza, Poesías completas, ed. de J. M. Morata Pérez, Diputación Provincial de Málaga, 1995, pág. 97. Véase A. Carreira, «Luis Martín de la Plaza o el manierismo en Antequera», Analecta Malacitana XX, 1, 1997, pág. 292.

80 E. Orozco, Los sonetos de Góngora (antología comentada), pág. 178.

81 Lo reproducimos en la edición de B. Ciplijauskaité (L. de Góngora, Sonetos, Madrid, Castalia, 1985): "Cosas, Celalba mía, he visto extrañas: / cascarse nubes, desbocarse vientos, /altas torres besar sus fundamentos, / y vomitar la tierra sus entrañas;/ duras puentes romper tal tiernas cañas;/ arroyos prodigiosos, ríos violentos, / mal vadeados de los pensamientos, / y enfrenados peor de las montañas; / los días de Noé, gentes subidas/en los más altos pinos levantados,/ en las robustas hayas más crecidas./ Pastores, perros, chozas y ganados/ sobre las aguas vi, sin forma y vidas, /y nada temí más que mis cuidados". 
sentimiento amoroso del sujeto lírico. Este soneto plantea, temática y estructuralmente, una analogía sustancial con la silva de Tejada que podemos cifrar en torno a tres aspectos. En primer lugar, la estructura compositiva manierista, pues se constata que:

como en otros sonetos amorosos de años anteriores, Góngora busca como motivo o elemento de referencia para expresar tal sentimiento una circunstancia de la vida de la naturaleza que, al igual que en otros casos, se desarrolla ampliamente hasta prolongarse a través de casi todos sus versos ${ }^{82}$.

El desplazamiento del tema amoroso tiene como contrapunto, de forma análoga a la silva de Tejada, a la naturaleza en una sus manifestaciones más vehementes: en el soneto gongorino se trata de una inundación y en la silva del antequerano de una tempestad. La diferencia fundamental radica en que Góngora toma la catástrofe de un suceso real y cercano, el desbordamiento del Guadalquivir, mientras que la narración de la tormenta en la silva de Tejada responde a la recreación de un topos de amplia andadura literaria. Late en el fondo de esta diferencia las dos posturas que definen el manierismo y el barroco: la elaboración intelectual frente al componente «real»y «vital» incipiente ya en las primeras composiciones del cordobés.

En segundo lugar, los cuadros descriptivos poseen una evidente plasticidad y fuerza pictórica que anticipan rasgos de la lírica barroca:

Esta suspensión del sentido o desviación de la atención para sorprender al final, aunque recurso de estructura compositiva manierista - según ya se anotó - se contrapesa por su predominante aspecto pictórico descriptivo, que lo mismo que su dramatismo y dinamismo obedece a un sentido barroco verdaderamente rubenesco ${ }^{83}$.

Y, por último, el carácter sublime o acento desmesurado en la descripción muestra una naturaleza vivificada lejos de la armonía de tópicos de la lírica del XVI como el locus amoenus. Así se subraya en los vv. 2-4 del soneto gongorino: «cascarse nubes, desbocarse vientos, / altas torres besar sus fundamentos / y vomitar la tierra sus entrañas». La silva tejadiana focaliza este carácter sublime de la naturaleza en el desbordamiento sensorial, a nivel auditivo - aliteraciones y diversos recursos de la armonía imitativa - y visual - la plasticidad descriptiva, el cromatismo o los matices del claroscuro - . Tanto la independencia que estos cuadros de paisaje cobran en este tipo de organización compositiva manierista como el carácter desmesurado ${ }^{84}$ que ostenta su descripción nos sitúan en la dirección de la estética barroca:

aunque el poeta lo halla tomado [la descripción de la catástrofe] como fondo o término de referencia o comparación al sentimiento amoroso, ello se impone por su fuerza y extensión tendiendo a quedarse solo, como tema predominante - achicando la figura-; busca la

82 E. Orozco, Los sonetos de Góngora (antología comentada), pág. 151.

83 E. Orozco, loc. cit., págs. 151-152.

84 Se pueden aducir otros textos que ostentan semejante equiparación de los desastres naturales con los efectos adversos del amor. Así sucede en los dos sonetos de Lope «Sufre la tempestad el que navega» $\mathrm{y}$ «Cadenas desherradas, eslabones» $\mathrm{y}$ en el de Quevedo «Ostentas de prodigios coronado». 
independencia de concepto de cuadro de paisaje cual no se da hasta el barroco. [...] en esa preterición de lo fundamental y en el hiperdesarrollo de lo secundario reside lo extremo de la estructura manierista; pero el subtema paisajístico que tiende a invadirlo todo es por sí, como forma y por sus elementos, exaltadamente barroco ${ }^{85}$.

Abandonando ya la hermosa pieza «Cosas, Celalba mía, he visto extrañas» otros sonetos gongorinos, en variada gradación de matices, se enmarcan en idéntica fórmula manierista con ese subtema privilegiado de la descripción de la Naturaleza. El soneto «Raya, dorado Sol, orna y colora» presenta la misma estructura, pero esta vez ofrece una Naturaleza idealizada más propia de la poesía renacentista. Como señala Orozco, es significativo que en su edición Vicuña pusiese al frente de este soneto el epígrafe Al río Guadalquivir, que baña los muros de Córdoba, «olvidando el motivo principal amoroso». El soneto «Ni en este monte, este aire, ni este río» responde, igualmente, a esa estructura manierista que pliega el tema de la naturaleza y el mitológico al amoroso en una organización sintáctica marcada por un esquema de correlaciones.

Es frecuente que la descriptio de la naturaleza se vetee de alusiones mitológicas o, más bien, que ésta se presente bajo el filtro de la mitología, dejando paso, entonces del bitematismo al pluritematismo al fundirse la descripción de la naturaleza con el componente mitológico, aunque no siempre se ofrezca la narración completa de la fábula mitológica que se presenta. Es el caso de sonetos como «Tras la bermeja Aurora, el Sol dorado» ${ }^{86}$ o el ya mencionado «Raya, dorado sol, orna y colora» ${ }^{87}$.

Junto a Góngora, otro poeta que cultivó ampliamente esta técnica de la pluritemática manierista fue Lope de Vega. El poeta madrileño aplicó este molde compositivo a distintas temáticas ${ }^{88}$. Pero en cuanto a lo que nos interesa ahora los

85 E.Orozco, Los sonetos de Góngora (antología comentada), págs. 152-153.

86 Subraya Orozco de este soneto el pluritematismo y el recurso del endecasílabo bimembre simétrico (E. Orozco, loc. cit., págs. 47-48).

87 Este soneto se ofrece como una variación del tema de la salida de la dama al campo y sus efectos sobre la naturaleza circundante (E. Orozco, loc. cit., págs. 53-54).

88 Aunque no coincidan exactamente con los tres núcleos temáticos que nos interesan para el estudio de la silva de Tejada, hay otros sonetos de Lope, particularmente en las Rimas (1604), que se adecuan a esa estructura manierista que venimos estudiando. El soneto «Assí en las olas de la mar ferozes», fechado en 1602, "presenta la estructura que Orozco llama manierista. Es una larga imprecación cuyo primer miembro, de estructura anafórica (assí...), ocupa los 11 primeros versos, y el segundo (el que contiene el tema) se concentra en los tres últimos» (Lope de Vega, Rimas, edición crítica y anotada de F. B. Pedraza Jiménez, Universidad de Castilla-La Mancha, 1993, vol. I, pág. 212). Igual sucede con el soneto «Vierte razimos la gloriosa palma», que «tiene una estructura acumulativa en sus once primeros versos, en los que propone siete ejemplos de esterilidad por falta de amor [...]. El tema se concentra en el último terceto, según la organización habitual en este tipo de poemas amorosos» (Lope de Vega, loc. cit., pág. 216). En la misma línea, podemos situar el soneto «Cubran tus aguas Betis caudaloso», que se desarrolla en torno a la confidencia al río hispalense cuya explicitación se reserva a los dos últimos versos (Lope de Vega, loc. cit., pág. 349). Y, finalmente, el soneto «Sufre la tempestad el que navega» que contrasta el descanso después del trabajo en diversas tareas con la inquietud constante del enamorado, quedando este término comparativo preterido al último terceto (Lope de Vega, loc. cit., pág. 355). 
textos que nos pueden servir de referentes explicativos se circunscriben al ámbito de poemas amorosos, casi exclusivamente sonetos, que reservan a los últimos versos la alusión amorosa. Ahora bien, dentro de este tipo de sonetos, son frecuentes un subgrupo en que se muestra el poder de la naturaleza (por ejemplo, las tempestades) a través de los elementos como contrapunto comparativo al sentimiento amoroso que se erige en fuerza superior a cuantas despliega la Naturaleza. Es el caso del soneto que reproducimos seguidamente en el que el tema secundario, la tempestad, pasa a primer plano - el propio título pone de manifiesto esta estructura bitemática - con la preterición del asunto principal a los últimos versos (A una tempestad ${ }^{89}$ ):

Con imperfectos círculos enlazan

rayos el aire, que, en discurso breve,
sepulta Guadarrama en densa nieve,
cuyo blanco parece que amenazan.
Los vientos campos y naves despedazan;
el arco el mar con los estremos beve;
súbele al polo, y otra vez le llueve;
con que la tierra, el mar y el cielo se abrazan.
Mezcló en un punto la disforme cara
la variedad con que se adorna el suelo,
perdiendo Febo de su curso el modo.
$\quad$ Y cuando ya parece que se para
el armonía del eterno cielo,
salió Lucinda y serenóse todo

Otro soneto que trata, aunque de forma más tangencial, la tempestad con el correlato amoroso que venimos subrayando es el que empieza «Bien fue de azero y bronze aquel primero», que presenta análoga «estructura manierista. Los doce primeros versos exponen la sobrecogida admiración que despierta el que se expone a los horrores del mar [...]. En el último terceto se le compara con el que se enfrenta a los peligros de la mujer» ${ }^{91}$.

Entre otros que podrían citarse, estos textos aquilatan sobradamente esta práctica poética que caracteriza la lírica escrita entre finales del XVI y principios del XVII.

\section{Fábula mitológica}

A la descripción de la naturaleza se añade la fábula mitológica como núcleo argumental predilecto de este tipo de organización compositiva manierista en la que

89 Lope de Vega, loc. cit., pág. 215.

90 B. Pedraza llama la atención sobre «su estructura manierista» y establece su cronología, no sin dudas, en torno a 1600. (Lope de Vega, loc. cit., pág. 214).

91 Lope de Vega, loc. cit., pág. 244. 
varios subtemas se entrelazan, relegando y reduciendo el núcleo temático principal a los últimos versos.

De nuevo Góngora es punto de partida y, también, seguro puerto. Podemos rastrear en distintos sonetos este bitematismo que comparte el asunto mitológico y la descripción de la naturaleza como submotivos vinculados, con distinta funcionalidad, a la temática amorosa principal. Es el caso del motivo del ruiseñor asociado a la fábula de Filomena en el soneto "Con diferencia tal, con gracia tanta» o la audacia de Faetón con la presencia de sus hermanas transformadas en olmos en «Verdes hermanas del audaz mozuelo» y «Gallardas plantas que con voz doliente». Un soneto menos conocido sobre el que llama la atención E. Orozco en la dirección que venimos señalando es el que empieza «Cisne gentil, después que crespo el vado». De nuevo «la expresión del sentimiento amoroso se traspone a un sólo verso del terceto final» ${ }^{92}$. La demora descriptiva en los dos cuartetos fija el contraste de color entre el verde y blanco cuyas potencialidades visuales subrayó el profesor granadino. En el primer terceto se introduce el mito de Leda y el cisne, reservando para el primer verso del último terceto la referencia al tema central: el tópico del efecto de la salida al campo de la dama ${ }^{93}$.

Junto al vate cordobés, Lope de Vega, principalmente en los sonetos incluidos en las Rimas, emplea la fábula mitológica en análoga estructura bitemática. «A Baco pide Midas que se buelva» (soneto XXI) presenta esta misma estructura compositiva donde «los once primeros versos son narración de la fábula [de Midas] y los tres últimos, aplicación al caso personal del poeta» ${ }^{94}$. El soneto «Que eternamente las cuarenta y nueve» reduce el tormento amoroso del sujeto lírico a los dos versos finales, mientras que los restantes quedan reservados a la ejemplificación de castigos míticos ${ }^{95}$.

\section{Los elementos.}

Restaría por comentar el papel de los elementos como subtema de la estructura manierista que venimos analizando. Los elementos ya habían gozado de relevante protagonismo en la lírica petrarquista, la cual desarrolló un campo metafórico de imágenes de la naturaleza en torno a los cuatro elementos cuyas fórmulas imaginísticas continuaron actuantes en la lírica barroca alejadas del contenido y tema inicial al que

92 E. Orozco, Los sonetos de Góngora (antología comentada), pág. 75.

93 E. Orozco, loc. cit., págs. 76-77.

94 Lope de Vega, Rimas, t. I, pág. 232. Pedraza lo fecha, aunque con dudas, entre 1600 y 1602.

95 Lope de Vega, loc. cit., t. I, pág. 304. Fechado entre 1597 y 1602. 
estaban vinculadas ${ }^{96}$. Aduciremos, pues, una serie de ejemplos que iluminen la línea explicativa que venimos desarrollando ciñéndonos al marco cronológico precedente a la silva, esto es, autores y textos de la segunda mitad del XVI. Es el caso de estos cuartetos del soneto «¿En qué puedo esperar contentamiento» de Hernando de Acuña ${ }^{97}$ :

¿En qué puedo esperar contentamiento,

si tras todo mi mal, señora mía, consiente mi fortuna que a porfía me venga ahora a dañar cada elemento?

Mis esperanzas se las lleva el viento, el fuego crece donde arder solía, llevóme el agua cuanto bien tenía y la tierra hará el apartamiento.

O estos tercetos del soneto «Alzo los ojos, de llorar cansados» de D. Hurtado de Mendoza:

Tendí todas las velas en bonanza, sin recelar humano impedimento;

alzóse una borrasca de mudanza, como si tierra y agua, fuego y viento, quisieran castigar mi confianza; yo suspiro, ardo y lloro y ya no siento ${ }^{98}$.

En la carta «Querría contar mi vida» del mismo, se recoge una mención a los elementos en un contexto de queja amorosa:
El fuego mi pecho enciende, el aire mis quejas lleva, el agua mis ojos ceba, la tierra cedo [sic] me atiende. Pues ya que los elementos que en el mundo nos sostienen se junten y me condenen, me salvan mis pensamientos ${ }^{99}$.

96 Entre la bibliografía más reciente es fundamental a este respecto la atención dedicada a los elemen-
tos en el volumen dirigido por J-P. Etienvre, Les Quatre Éléments dans les littératures d'Espagne (XVI' et
$X V I I^{e}$ siècles), Presses de l'Université Paris-Sorbonne, 2004. Se estudia este tema en poetas como Fer-
nando de Herrera (L. Schwartz), san Juan de la Cruz (G. Serés), en las silvas a los elementos de la Poética
silva (B. López Bueno y M. Blanco), en la poesía amorosa y en la obra moral de Quevedo (A. Carreira
y A. Rey), y en una loa de sor Juana Inés de la Cruz (J. Roses). Junto al análisis de los elementos en el
género poético se dedican capítulos análogos a la novela y dramaturgia áurea junto al la relación de este
tema con la emblemática, analizada por S. Lopéz Poza. 97 H. de Acuña, Varias poesías, ed. de L. F. Díaz Larios, Madrid, Cátedra, 1982, pág. 331, vv. 1-8.

98 D. Hurtado de Mendoza, Poesía completa, ed., introd., y notas de J. I. Díez Fernández, Barcelona, Planeta, 1989, pág. 82.

99 D. Hurtado de Mendoza, loc. cit., pág. 152. 
En la poesía de Fernando de Herrera se encuentran, asimismo, ejemplos notables. La canción «Deciende de la cumbre del Parnaso» ${ }^{100}$ - fechada por Coster con posterioridad al año 1971 - contiene la siguiente estancia (vv. 91-105):

Todo cuanto al terreno cuerpo alienta,
por la celeste fuerça deduzido,
se halla en vos casi en igual efeto;.
de vos el fixo globo, i el tendido
umor, i el vago cerco se sustenta,
i el ardor de las llamas inquïeto;
que con vigor secreto
a tierra i agua, 'l aire, i puro fuego,
cual eteria [sic] virtud i las estrellas,
son vuestras obras bellas
la tierra, l'agua, el aire, 'l puro fuego;
¡ô glorioso cielo en nuestro suelo!,
¡ô suelo glorioso con tal cielo!:
¿quién podrá celebrar vuestra nobleza?;
¿quién osará alabar vuestra belleza?

En otras canciones hallamos alusiones similares, como en la que empieza «Jamás alzó las alas alto al cielo ${ }^{101}$ en la que los elementos sirven de término comparativo a los atributos de la dama (vv. 37-39):

$$
\begin{aligned}
& \text { que vuestro resplandor esclareçido } \\
& \text { a tierra y mar y ayre alumbra, y muestra } \\
& \text { quánto es mayor la ilustre lumbre vuestra. }
\end{aligned}
$$

En el envío de la canción «Amor, tú qu'en los tiernos, bellos ojos» la alusión a los cuatro elementos marca la sumisión a que Amor condena a los amadores:

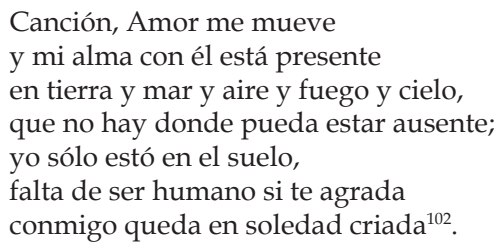

El planteamiento de la canción es similar en la silva de Tejada, pues esta se configura como un apóstrofe al dios Amor en el que se proclama su superioridad sobre los dioses del Olimpo y sobre la misma naturaleza significada en sus cuatro elementos:

Tú, sacro Amor, que con doradas alas atraviesas del Austro al Orïente

100 F. de Herrera, Poesía castellana original completa, ed. de C. Cuevas, Madrid, Cátedra, 1997² ed, págs. 599-600.

101 F. de Herrera, loc. cit., pág. 293.

102 CORDE: http://corpus.rae.es/cordenet.html 
y abres con tu fuerza el mar sonante,

y a Febo, al arrogante

Marte vences, subiendo, y alto igualas

a Jove, y sobrepujas tú, presente [...] (vv. 129-135)

y todo el bien, Amor, de tu ser viene

y el ancho mundo en tu poder sostiene (vv. 159-160)

Al margen de una estructura manierista que de acogida a estos temas que estamos analizando, Lope hizo referencia en algunas ocasiones a los cuatro elementos en distintos contextos temáticos ${ }^{103}$. Nos interesa, especialmente un soneto en el que pone en relación los cuatro elementos con el Amor ${ }^{104}$ :

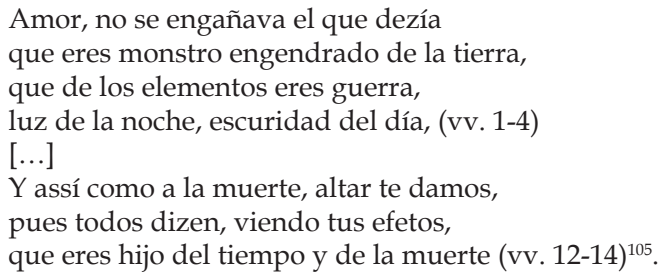

Incursiones azarosas por la lírica áurea revelan la constante presencia de los elementos en la poesía española del siglo de oro. Señalo, por ejemplo, la sextina ${ }^{106}$

103 Me refiero, principalmente, a sonetos de temática religiosa. Por ejemplo el terceto del soneto LXXXV («Dulce Señor, mis vanos pensamientos») de las Rimas sacras, vv. 12-14: «Ponme a la sombra de tu cruz divina / y vengan contra mí fuego, aire, tierra, / mar, hierro, engaño, envidia, infierno y muerte» (Lope de Vega, Obras poéticas, edición, introducción y notas de José Ma Blecua, Barcelona, Planeta, 1983, pág. 362); o el soneto IX («Una vez que habló Dios el día tercero»), vv. 9-11: «Puso ley a las aguas convenible, / la tierra descubrió, dio al aire esfera, / y al fuego duración sin combustible» (Lope de Vega, loc. cit., pág. 320). Estos dos textos ofrecen dos versiones contrapuestas de Dios como creador de la armonía elemental que puso orden y dio fundamento al universo. Más interesante es el segundo en tanto en cuanto presenta, como la silva de Tejada, la preterición de la instancia del sujeto lírico a los versos finales. El último soneto de las Rimas sacras que aducimos «Adonde quiera que su luz aplican» desarrolla en el cuarteto y terceto centrales la correspondencia entre los elementos y la variedad del mundo de la que Dios es artífice (vv. 5-11): «si a la tierra se bajan, y se implican / en tanta variedad, Naturaleza / les muestra tu poder con la destreza / que sus diversidades significan; / si al mar, Señor, o al aire, meditando / aves y peces, todo está diciendo / que es Dios su autor, a quien está adorando» (Lope de Vega, loc. cit., pág. 335). En el mismo contexto religioso se proyectan las alusiones a los elementos en el romance A la soledad de nuestra señora, vv. 9-14: «[...] sin tierra, que todo es sangre, / sin aire, que todo es fuego, / $\sin$ fuego, que todo es agua, / sin agua, que todo es hielo; / con la mayor soledad / que humanos pechos se vieron [...]» (Lope de Vega, loc. cit., pág. 449).

104 Respecto a la relación del amor con los elementos puede resultar ilustrativo este otro soneto de $E l$ dómine Lucas: «Si Amor sus flechas y el infierno el fuego, / perdido hubieran, de mi pecho ardiente, / para matar y atormentar la gente, / fuego y flechas sacar pudieran luego. / Y si a Neptuno, que en mi llanto anego, / faltara el agua y la inmortal corriente, / hallara nuevo mar en la gran fuente / de lágrimas que ya me tienen ciego. / Y si al áspid soberbio e iracundo / faltara la ponzoña de su aliento, / la hallara de mi pecho en lo profundo. / Y si faltara al ave su elemento, / con mis suspiros sustentara el mundo, / que soy ponzoña, fuego, mar y viento» CORDE: http://corpus.rae.es/cordenet.html.

105 Lope de Vega, loc. cit., pág. 503.

106 J. M. Blecua, «El manuscrito 82/3/39 de la Biblioteca Colombina», en Homenaje a Alonso Zamora Vicente. III. Literatura española de los siglos XVI-XVII, Madrid, Castalia, 1992, vol. II, págs. 19-46, págs. 40-41. 
anónima recogida en el ms. 82/3/39 de la Biblioteca Colombina de Sevilla de la que consignamos la estrofa de apertura y la de cierre, que presentan análogas alusiones a los elementos en una contextualización amorosa:

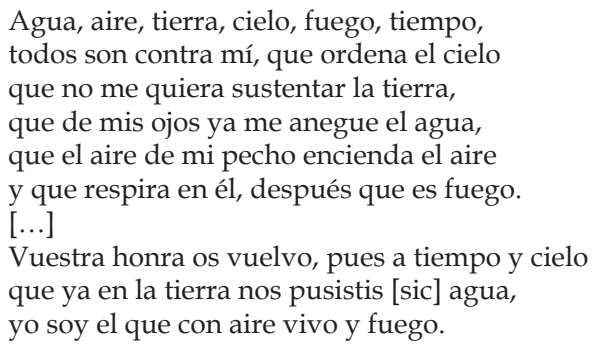

$\mathrm{O}$, igualmente, el soneto recogido en Las honras que celebró la famosa y gran ciudad de Granada en la muerte de la serenísima reina de España doña Margarita de Austria, mujer del Rey don Felipe tercero nuestro señor, en 13 de octubre de 1611, con toda la descripción de los reales túmulos y los demás trabajos de ingenio de Pedro Rodríguez de Ardila ${ }^{107}$, en este caso en un contexto fúnebre, vuelve a aparecer el motivo de los elementos:

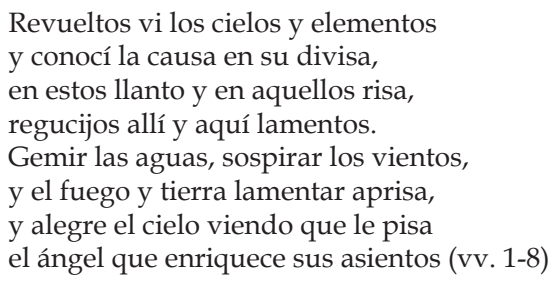

Se podría ampliar el ejemplario a la presencia de los elementos en autores barrocos, continuando la línea perfilada en la lírica renacentista. No obstante, de lo que hemos intentado dar cuenta es de la representación y valencias textuales de éstos en la lírica en torno al tránsito del manierismo al barroco para determinar el ámbito de escritura de estos textos que responden a la práctica manierista estudiada.

Querríamos acabar con una mención al italiano L. Groto, cuya lírica sobresale por el tratamiento de los elementos y la temática amorosa en una estructura decididamente manierista. Como ha sido ya señalado ampliamente por J. Fucilla, J. M. Blecua, J. M. Micó o A. Carreira es modelo reiteradamente imitado por los poetas españoles áureos especialmente Góngora o Quevedo ${ }^{108}$.

107 Granada, Bartolomé Lorenzana, 1612, fol. 28r.

108 J. M. Micó señaló respecto al soneto gongorino de juventud ya citado «Ni en este monte, este aire, ni este río» que está «modelado en parte a imitación de Luigi Groto» (J. M. Micó, «Góngora, poeta elemental», J-P. Etienvre (dir.), Les Quatre Éléments dans les littératures d'Espagne (XVI'et XVII ${ }^{e}$ siècles), págs. 119-129 (cita, pág. 120). Igualmente A. Carreira subrayaba la influencia del poeta italiano en Quevedo: «Este poeta hoy desconocido, editado al menos en 1578 y muerto en 1585, aficionadísimo a jugar con los elementos y con las palabras, incluso en sus poemas latinos, resulta ser, entre los italianos, el más ex- 
Las Rime di Lvigi Groto, Cieco d'Hadria, Venecia, $1610^{109}$ recogen una amplia variedad de textos líricos dedicados a los elementos, de los que hemos seleccionado los más significativos. En una «corona de dodeci seguenti Sonetti alla Signora Alessandra Volta», el cuarto reza así (fol. 3v): «O senno antico in giouanile aspecto», vv. 5-8: «Di natura, ò di noi solo diletto, / che fai la terra, il mar, l'aere giocondo, / de più dotti scrittor soave pondo, / dolce d'ogni occhio,e d'ogni orecchia oggetto».

Otro texto muy interesante del autor italiano es el soneto «Efetti nell' Amanti» (parte prima, fol. 18r) que, como anticipa el título, recoge una serie de fenómenos y elementos naturales adversos para equipararlos a los efectos del Amor sobre el amante:

Quasi il gran mondo nel mio amor discerno.

La terra, e la mia fe, che allhora trema

s'auuien che terremoto entro a lei frema,

di gelosia lo mio duolo el'inferno,

El'acqua il pianto mio la state, $e^{\prime} l$ verno

l'ardire ardente, e la gelata tema.

La luna e il mio sperar, che cresce, e scema

del mio sol la memoria e un Sole eterno.

Le gratie, e gli arte fuoi nel cor mio impressi,

sono le stelle assisse a l'altre sfere.

L'arder mio occolto, èl' inuisibil foco.

Le spesse tempestà, gli sdegni spessi,

l'aere i sospiri, e'l tutto al fin v'ha loco,

fuor che bonaccie, Autunni, Primauere.

Otras alusiones a los elementos se integran en la temática mitológica como en la siguiente octava dirigida a Ícaro (parte prima fol. 69r, Icaro)

La terra in torre mi ferrò, e mi tenne,

sciolsemi il padre, giunse l'ali al late.

Il foco strusse le incerate penne,

e mi lascio de piume di farmato.

L'Aria percossa in van mal mi sostenne.

Nel acqua al fin prouai l'ultimo fato.

Ondi i quattri elementi lega e guerra

contra me fecer, Foco, Aer, Acqua e Terra.

Asimismo son recurrentes las referencias a los elementos en semejante contexto amoroso con la asociación de cada uno de éstos al animal cuyo hábitat se halla determinado por las cualidades de éstos. Así en el soneto «Tormenti amorosi» (parte seconda, fol. 50r) que empieza «Se io la sfera del foco accolta hauessi», en la

plotado por el Quevedo amoroso» (A. Carreira, «Agua y fuego en la poesía amorosa de Quevedo», J-P. Etienvre (dir.), Les Quatre Éléments dans les littératures d'Espagne (XVI et XVII siècles), págs. 85-97 (cita, pág. 86-87) ; señala la influencia de Groto, asimismo, en reiteradas ocasiones : págs. 88, 92, 94

109 BNE, Sala General, sig. 3/26027-9 (3 vols). 
composición «Stato infelice» (parte seconda, fol. 53r), o en el soneto que empieza «Non moue, erge, apre il corpo, i piedi l'ale» (parte seconda, fol. 155r).

En otros casos la mención a los cuatro elementos se integra en una composición orquestada por una estructura diseminativo-recolectiva como la titulada «Amante consumato» (parte prima, fol. 22r): «Gli elementi, ond'a ha vita ognum di noi / si consumano in me, donna, per voi. / Il foco appoggio al natural calore, / si spinge a quel, cõ cui m'infiamma amore. / L'aer, che fà, ch'io spiri, / si consuma in sospiri. / L'acqua, che ministrar gli humor costuma, / in pianto si consuma. / La terra, ond'ho le mẽbra, in preghi, e'n passi, / per piani, e poggi consumando vassi. / Cosi la vostra inessorabil guerra / in me consuma Foco, Aere, Acqua e Terra» ${ }^{110}$.

\section{A modo de sintesis}

Como hemos visto, se imponen en estos textos la duplicidad temática (tema amoroso y descripción de la Naturaleza o tema amoroso y motivos mitológicos) o el pluritematismo (tema amoroso, descripción de la Naturaleza, fábula mitológica y alusiones a los elementos). Derivado de ese efecto de desintegración de que hablábamos, cada tema cobra cierta autonomía y desarrollo particulares en el entramado textual en que se integran, de forma que las descripciones de la Naturaleza se recrean en remansos coloristas y preciosistas y los motivos mitológicos adquieren particular desarrollo narrativo:

la simultánea valoración de los varios elementos de la composición y su distribución en el conjunto de la obra de acuerdo con una rígida y meditada estructura desintegradora que les hace valer por sí con independencia y, al mismo tiempo, los enlaza con un sentido no natural ni derivado de la realidad, sino impuesto por una intelectual intención artística ${ }^{111}$.

Este diseño estructural se acompaña del despliegue de una serie de recursos estilísticos que reproducen en el plano formal las correspondencias temáticas originadas por esa organización pluritemática, principalmente algún elemento que subraye ese

110 Igualmente en otros contextos ajenos al amoroso se insertan alusiones a los elementos de acuerdo a una estructura diseminativa-recolectiva como en la octava titulada Notabile caso (terza parte, fol. 73r) «Lascia un figlio nel bagno, el'altro corre. / La Madre, il qual caduto il foco incende, / ne quel, ne questo a tempo poi soccorre, / e in terra di dolor morta si stende, / con cui lo sposo appeso si concorre, / vn'arde, vn si sommerge, un cade, un pende, / sono i quattro elementi à quattro, poco, / cui tomba san, terra, acqua, aere, e foco.». También en el ámbito de la poesía epidíctica encontramos las mismas alusiones, así en esta octava (fol. 113r) del Epitalamio nelle nozze della Si. Faletta (terza parte, fol. 109r-115r): «Mouete poscia, ò Muse scelti accenti / a lodar questo di scelte parole, / pregate pioggie, neui, nebbie, e venti. / che non facciano oltraggio à un tal Sole. / Tutti insieme pregate gli Elementi. / Che voglia uno in tal dì, quel, che altro vuole / si che segno non mostrino di guerra / l'Acqua il Foco in tal dì l'Aria, e la Terra».

111 E. Orozco, «Estructura manierista y estructura barroca en poesía (con el comentario de unos sonetos de Góngora», pág. 187. 
tema central relegado en espacio y jerarquía narrativa y que, paralelamente, llame la atención del lector sobre ese elemento final:

Habrá, sí, recursos sobre todo racionales, sintácticos y dibujísticos - frente a la orientación sensorial que trae el barroco - que en ambas artes encauzan la atención hacia esa parte o punto último desvalorado o lejano en la composición. También la complicada estructura métrico-sintáctica, como la ordenación de los planos de composición [...] se ofrecen como esquemas previos a los que se acomoda la expresión y elementos en consciente alarde técnico ${ }^{112}$.

Dos recursos son reiteradamente empleados por el antequerano en la «Silva al elemento del aire»: la comparación - del sentimiento del sujeto lírico con los motivos derivados de los núcleos temáticos principales: la catástrofe natural causada por la tempestad y el poder de los cuatro elementos, particularmente la fuerza del viento, - y la hipérbole. En el plano enunciativo queda marcado el contraste, en la última octava, del sujeto lírico en primera persona frente al tono narrativo y descriptivo anteriores. Todos estos recursos orquestan y cohesionan la variada red de elementos tejida en torno a esta estructura manierista.

\section{Conclusión}

Este estudio ha tratado de aunar dos perspectivas complementarias: una que podríamos llamar microtextual, que se centra en el análisis de la «Silva al elemento del Aire» del poeta antequerano A. de Tejada Paéz, y otra macrotextual que ha aspirado a definir la funcionalidad de la fábula mitológica en el entramado de la pluritemática manierista a través de los textos más representativos de tal práctica poética. Para ello hemos revisado con cierto pormenor los sonetos de L. de Góngora y de Lope de Vega escritos en las décadas de finales del Seiscientos, los recogidos en la antología manierista de las Flores de poetas ilustres, y, finalmente, algunas de las composiciones del italiano L. Grotto recogidas en sus Rime.

Estos textos ejemplifican el cultivo de un tipo de organización discursiva que integra diversos elementos temáticos - entre ellos la fábula mitológica - en una estructura desintegradora que responde a los principios estéticos intelectualizantes del Manierismo. Han quedado definidos los tres núcleos o motivos que articulan la red pluritemática, enmarcados por el tema amoroso al que sirven de contraposición: la descripción de la naturaleza, que avanza signos del poema descriptivo barroco; la fábula mitológica; y la teoría de los elementos, relacionada igualmente por tu temática cosmogónica con los poemas barrocos de la creación del mundo. 
La «Silva al elemento del aire» de A. de Tejada Páez integra diversas sendas que serán ampliamente transitadas en la lírica del Setecientos: el despliegue descriptivo (poema descriptivo barroco), la temática cosmogónica (poemas de creación del mundo) y la combinación de la fábula mitológica ovidiana con la inventio original (fábula mitológica barroca). La forma de integrar esos elementos en una sola composición se efectúa mediante un tipo de organización discursiva que responde a los principios del manierismo literario y pictórico, la cual aspira, como decía Cervantes en el Quijote, a componer «una tela de varios y hermosos lazos tejida, que, después de acabada, tal perfección y hermosura muestre, que consiga el fin que se pretende en los escritos, que es enseñar y deleitar juntamente». 